\title{
A critical review of synthesis parameters affecting the properties of zinc oxide nanoparticle and its application in wastewater treatment
}

\author{
E. Y. Shaba ${ }^{1}$ - J. O. Jacob ${ }^{1} \cdot$ J. O. Tijani ${ }^{1} \cdot$ M. A. T. Suleiman ${ }^{1}$
}

Received: 5 October 2020 / Accepted: 18 January 2021 / Published online: 13 February 2021

(c) The Author(s) 2021

\begin{abstract}
In this era, nanotechnology is gaining enormous popularity due to its ability to reduce metals, metalloids and metal oxides into their nanosize, which essentially alter their physical, chemical, and optical properties. Zinc oxide nanoparticle is one of the most important semiconductor metal oxides with diverse applications in the field of material science. However, several factors, such as $\mathrm{pH}$ of the reaction mixture, calcination temperature, reaction time, stirring speed, nature of capping agents, and concentration of metal precursors, greatly affect the properties of the zinc oxide nanoparticles and their applications. This review focuses on the influence of the synthesis parameters on the morphology, mineralogical phase, textural properties, microstructures, and size of the zinc oxide nanoparticles. In addition, the review also examined the application of zinc oxides as nanoadsorbent for the removal of heavy metals from wastewater.
\end{abstract}

Keywords Zinc oxide $\cdot$ Synthesis parameters $\cdot$ Nanoadsorbent $\cdot$ Heavy metals

\section{Introduction}

Zinc oxide nanoparticles constitute one of the important metal oxides materials that have been widely applied in materials science due to its unique physical, chemical, and biological properties such as biocompatible, environmentally friendly, low cost and non-toxic nature (Alwan et al. 2015; Salahuddin et al. 2015; Ruszkiewicz et al. 2017). Owing to its exceptional properties, $\mathrm{ZnO}$ nanoparticles have been applied as a functional advanced material to solve different societal problems especially in the field of catalysis for wastewater treatment and also as cosmetics and antimicrobial additives (Ruszkiewicz et al. 2017). ZnO nanoparticles have several advantages which include unique chemical and thermal stability, robustness, and long shelf life over other metal oxides such as $\mathrm{TiO}_{2}, \mathrm{WO}_{3}, \mathrm{SiO}_{2}$, and $\mathrm{Fe}_{2} \mathrm{O}_{3}$. $\mathrm{Zinc}$ oxide exists in the following phases: hexagonal quartzite, cubic zinc blende, and cubic rock salt (Belver et al. 2019). The wurtzite structure is the most common due to its stability at ambient conditions, where every zinc atom is tetrahedrally coordinated with four oxygen atoms (Barhoum et al.

E. Y. Shaba

elijah.shaba@futminna.edu.ng

1 Department of Chemistry, Federal University of Technology, P. M. B. 65, Minna, Niger State, Nigeria
2019). In each phase, zinc oxide nanoparticles (ZnONPs) are a semiconductor material with a direct wide bandgap of $\sim 3.3 \mathrm{eV}$ (Senol et al. 2020). It has advantages such as stabilization on substrate especially the zincblende form with a cubic lattice structure (Parihar et al. 2018). Food and Drug Administration (FDA) includes also zinc oxide as one of the safest metal oxides that can be used in food industries (Bettini et al. 2016).

Zinc oxide nanoparticles have been synthesized via different chemical and physical methods, namely sol-gel, hydrothermal, precipitation and co-precipitation, chemical vapour deposition, spray pyrolysis, magnetic sputtering, microwave-assisted technique, solvothermal, biological routes amongst others (Ul-Haq et al. 2017). Each of the listed methods has advantages and disadvantages and as such different morphologies of $\mathrm{ZnO}$ nanoparticles according to characterization tools ranging from nanoplates, nanostars, nanobelts, nanotubes have been reported (Ambika and Sundararajan 2015). Different zinc salts such as zinc acetate dehydrate $\left.\left(\mathrm{ZN}\left(\mathrm{C}_{2} \mathrm{H}_{3} \mathrm{O}_{2}\right)_{2} \cdot 2 \mathrm{H}_{2} \mathrm{O}\right)\right)$, zinc nitrate hexahydrate $\left(\mathrm{Zn}\left(\mathrm{NO}_{3}\right)_{2} \cdot 6 \mathrm{H}_{2} \mathrm{O}\right)$ zinc sulfate $\left(\mathrm{Zn}\left(\mathrm{SO}_{4}\right)_{2} \cdot 7 \mathrm{H}_{2} \mathrm{O}\right)$ and zinc chloride $\left(\mathrm{ZnCl}_{2}\right)$ as precursor have been used to prepare $\mathrm{ZnO}$ nanoparticles (Ambika and Sundararajan 2015; Ezhilarasi et al. 2016; Sierra et al. 2018).

However, the problems of stability, dispersion and crystalline structures control of $\mathrm{ZnO}$ nanoparticles in aqueous 
medium constitute a serious bottleneck to industrial application of the material. In order to surmount the challenges, many researchers have focused on the investigation of factors affecting the properties of stable zinc oxidesnanoparticles (Yu and Dong 2016). These factors include $\mathrm{pH}$ of the reaction mixture, synthesis and calcination temperature, reaction time, concentrations of precursors, solvent medium and surfactant concentration among others (Hajiashafi and Motakef-Kazemi 2018). The aforementioned factors directly influence the particle size, morphology, phase, and surface area of the zinc oxide nanoparticles (Hajiashafi and Motakef-Kazemi 2018; Perillo et al. 2018; Jamal et al. 2019).

Zinc oxide nanoparticles display some properties such as high chemical and thermal stability, unsaturated surfaces, and excellent adsorption behaviour towards organic and inorganic pollutants in aqueous matrix. ZnO nanoparticles possess higher photon absorption efficiency, high surface area, and oxidizing power compared to the other semiconductors and are easily available, non-toxic, and cost-effective for the purification of wastewater (Ray and Shipley 2015). These characteristics have encouraged many scientists in recent years to study the adsorptive potentials of $\mathrm{ZnO}$ nanoparticles for the removal of heavy metals from industrial wastewater (Yuvaraja et al. 2018). Different shapes of $\mathrm{ZnO}$ nanoparticles have been reported to have high removal efficiency for heavy metals. For instance, a spherical shape $\mathrm{ZnO}$ nanoparticles removed lead $\left(\mathrm{Pb}^{2+}\right)$, cadmium $\left(\mathrm{Cd}^{2+}\right)$ and mercury $\left(\mathrm{Hg}^{2+}\right)$ from aqueous solution (Angelin et al. 2015). Additionally, $\mathrm{ZnO}$ nanorods, flowers and nanocubes were used as nanoadsorbent to remove arsenic $\left(\mathrm{As}^{3+}\right)$, chromium $\left(\mathrm{Cr}^{6+}\right)$ from wastewater (Yuvaraja et al. 2018). Several researchers have synthesized $\mathrm{ZnO}$ nanoparticles based on the variation of different process parameters such as $\mathrm{pH}$, stirring speed, reaction time, reaction temperature, mixing ratio, calcination temperature and precursor concentration. However, there is a paucity of information on the comprehensive review on the effects of these synthesis parameters on the shape, size, and phase of zinc oxides. Not only that, the application of $\mathrm{ZnO}$ nanoparticles as nanoadsorbent has also not been comprehensively reported by researchers. Herein, the review of some of these process parameters such as the effect of $\mathrm{pH}$, reaction time, and synthesis and calcination temperature on the properties of zinc oxide nanoparticles such as morphology, crystallite size, and surface area is provided. The review also focuses on the application of $\mathrm{ZnO}$ nanoparticles as nanoadsorbent for the removal of heavy metals in different wastewater.

\section{Crystal structure of zinc oxide nanoparticles}

Zinc oxide $(\mathrm{ZnO})$ is a water insoluble white powder used as an additive in different products especially foods, paints, sunscreens, lubricants, sealants, and batteries (Chandramohan et al. 2017; Perveena et al. 2020). Although ZnO occurs naturally as the mineral zincite, most zinc oxides are chemically produced under different conditions in the laboratory. Zinc oxide nanoparticles can exist in three forms, namely hexagonal-wurtzite, cubic zincblende, and cubic rocksalt (see Fig. 1). The shaded black and gray spheres represent oxygen and zinc atoms (Wang and Zhang 2005). The wurtzite structure is most common and stable at ambient conditions due to its ionicity that resides exactly at the borderline between the covalent and the ionic materials (Chandramohan et al. 2017). The zinc blend $\mathrm{ZnO}$ structure can only be stabilized by growing on cubic substrates and the rocksalt structure can be obtained at relatively high pressures, $10 \mathrm{GPa}$ (Özgür et al. 2005). As found with most group II-VI elements, the bonding in $\mathrm{ZnO}$ is largely ionic with $0.074 \mathrm{~nm}$ for zinc ions $\left(\mathrm{Zn}^{2+}\right)$ and $0.140 \mathrm{~nm}$ for the oxygen ion $\left(\mathrm{O}^{2-}\right)$ as corresponding radii. This property is responsible for the preferential formation of wurtzite rather than zinc blend structure (Phillips), as well as its high piezoelectricity.

\section{Classification of zinc oxide nanomaterials}

Classification of $\mathrm{ZnO}$ nanoparticles is based on the number of dimensions, which are not confined to the nanoscale range $(<100 \mathrm{~nm})$. The main types based on the dimensions and structures are: zero-dimensional (0D), one-dimensional (1D), two-dimensional (2D), and three-dimensional (3D) nanomaterials (Zhang et al. 2018) and their detail descriptions and morphological properties are provided in Table 1.

\section{Morphology of ZnONPs}

Different morphologies of zinc oxide nanoparticles have been reported by researchers due to the variation of various process parameters. These include nanorods (Ghannam et al. 2019), nanowires (Hu et al. 2007), nanospheres (Nejati et al. 2016), nanoflowers (Peng et al. 2013), nanotubes (Wang and Cui 2009), nanotetrapods (Jin et al. 2013), nanoplate (Tan et al. 2015) and nanotripods (Azhar et al. 2017). The formation of different morphologies of $\mathrm{ZnO}$ nanoparticles shown in Table 2 depends on the applied synthesis conditions.

Table 2 shows a description of different morphologies of $\mathrm{ZnO}$ nanoparticles synthesized by different researchers. The table revealed different morphologies of $\mathrm{ZnO}$ nanoparticle such as nanospheres, nanorods, nanoflowers, 
(a)

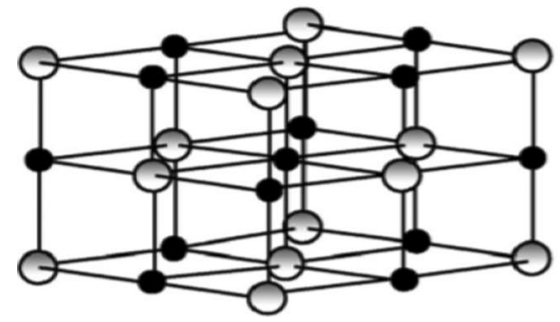

(b)

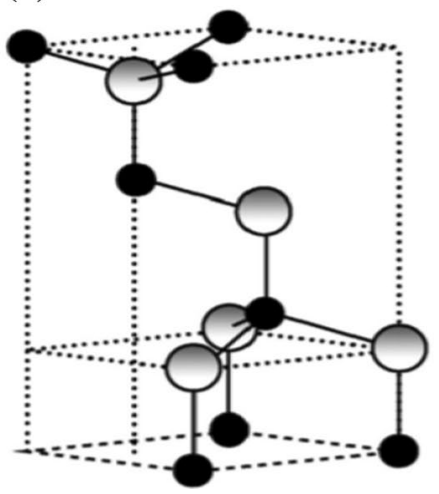

(c)

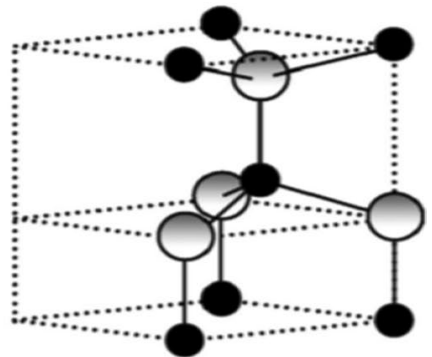

Fig. 1 Different phases/network structures of $\mathrm{ZnO}$ nanoparticles a cubic rocksalt, $\mathbf{b}$ cubic zincblende, $\mathbf{c}$ Hexagonal-Wurtzite

Table 1 Different dimension and descriptions of zinc oxide nanoparticles

\begin{tabular}{|c|c|c|c|c|}
\hline Dimensional & Description & Nanomaterial type & Morphology & References \\
\hline Zero dimensional (0D) & $\begin{array}{l}\text { All the dimensions (Length, breadth, } \\
\text { and heights) are in existence in the } \\
\text { nanoscale }(<100 \mathrm{~nm}) \text {, 0D nanostructures } \\
\text { are the simplest building blocks that can } \\
\text { be used to design and create 1D, 2D, and } \\
\text { complex 3D nanostructures }\end{array}$ & $\begin{array}{l}\text { Nanoparticles and nano- } \\
\text { dots }\end{array}$ & & Cao (2017) \\
\hline One dimensional (1D) & $\begin{array}{l}\text { Two dimensions are in the nanoscale } \\
(1-100 \mathrm{~nm}) \text { and the other one dimensions } \\
\text { in macroscale }\end{array}$ & $\begin{array}{l}\text { Two dimensions nanoma- } \\
\text { terials have needles like- } \\
\text { shaped such as nanow- } \\
\text { ires, nanofib- } \\
\text { ers, nanorods, } \\
\text { nanocapsule, nanowalls } \\
\text { and nanotubes }\end{array}$ & & $\begin{array}{l}\text { Nasrollahzadeh et al. } \\
\text { (2019) }\end{array}$ \\
\hline Two dimensional (2D) & $\begin{array}{l}\text { In two-dimensional nanomaterial (2D), the } \\
\text { two dimensions are outside the nanoscale }\end{array}$ & $\begin{array}{l}\text { They exhibit plate-like } \\
\text { shapes such as nano- } \\
\text { films, nano- } \\
\text { plates nanolay- } \\
\text { ers, and nanocoatings }\end{array}$ & & Leonardi (2017) \\
\hline Three dimensional (3D) & $\begin{array}{l}\text { The three dimen- } \\
\text { sions are not in nanoscale and all dimen- } \\
\text { sions are in macroscale }\end{array}$ & Nanocomposites & & Tseng et al. (2012) \\
\hline
\end{tabular}

nanotubes, nanotetrapods, nanoplates and nanotripods obtained under different synthesis conditions and synthesis methods in the laboratory. The formation of the desired shape of $\mathrm{ZnO}$ nanoparticles depends on the role played synthesis parameters such as solution $\mathrm{pH}$, template agents, reaction temperature, reaction time, stirring speed, solvent types, calcination temperature, calcination time and others. The effects of some of the aforementioned factors on the properties of ZnONPs irrespective of the synthesis approach are explained as follows:

\section{Factors influencing the synthesis of ZnO nanoparticles}

\section{$\mathrm{pH}$ of reaction mixture}

$\mathrm{pH}$ of the reaction mixture determines the types of $\mathrm{ZnO}$ nanoparticles formed (Aziz and Jassim 2018). The crystallite size, morphology, phases, and surface areas of $\mathrm{ZnO}$ nanoparticles depend largely on the amount of positively and negatively charge ions present in the medium dur- 
Table 2 Different morphology of zinc oxides methods and reaction conditions of $\mathrm{ZnO}$ nanoparticles

\begin{tabular}{|c|c|c|c|c|}
\hline Nanomaterial & Method of Synthesis & Description & Morphology & References \\
\hline Nanotubes & Chemical Precipitation & $\begin{array}{l}\text { A nanotube is a tube-like struc- } \\
\text { ture that belong to one-dimen- } \\
\text { sional (1D) nanostructure group } \\
\text { (Erhard and Holleitner 2015) }\end{array}$ & & Wang and Cui (2009) \\
\hline Nanotetrapod & Chemical vapour transport & $\begin{array}{l}\text { Nanotetrapods are nanomaterial with } \\
\text { four feet that belong to the dimen- } \\
\text { sional structure. The advantage of } \\
\text { nanotetrapods over other nanocrys- } \\
\text { talline geometric shapes of } \\
\text { nanomaterials includes alignment } \\
\text { with themselves spontaneously } \\
\text { to the plane with one standard } \\
\text { 'arm' (Marcus et al. 2007). ZnO } \\
\text { nanotetrapod legs are spatially } \\
\text { distributed with an angle of } 109.5^{\circ} \\
\text { (Modi 2015) }\end{array}$ & & Jin et al. (2013) \\
\hline Nanosphere & Precipitation & $\begin{array}{l}\text { The nanosphere is the sim- } \\
\text { plest form of nanoparti- } \\
\text { cle with only one adjustable geo- } \\
\text { metric parameter (radius) exhibit- } \\
\text { ing resonant responses under optica- } \\
\text { lexcitation (Ahmadivand et al. } \\
\text { 2016) }\end{array}$ & & Geetha et al. (2016) \\
\hline Nanowires & Hydrothermal & $\begin{array}{l}\text { Nanowire is a solid rod-like structure } \\
\text { having thickness or diameter con- } \\
\text { strained to tens of nanometers or } \\
\text { less }\left(1 \mathrm{~nm}=10^{-9} \mathrm{~m} \text { ) that is similar }\right. \\
\text { to conventional wires (Waqar et al. } \\
\text { 2015). Nanowires are known as 1D } \\
\text { material due to the large differ- } \\
\text { ence between their diameter and } \\
\text { length (Nasrollahzadeh et al. 2019). } \\
\text { Nanowires have been reported to } \\
\text { have fewer structural defects over } \\
\text { their bulk counterpart (Erhard and } \\
\text { Holleitner 2015) }\end{array}$ & tiente & Hu et al. (2007) \\
\hline Nanoflowers & Hydrothermal & $\begin{array}{l}\text { Nanoflowers are nanostructure simi- } \\
\text { lar to plant flowers in a nanoscale } \\
\text { range that is usually prepared in } \\
\text { extreme conditions like } 80-550^{\circ} \mathrm{C} \\
\text { (Shende et al. 2018). Nanoflowers } \\
\text { have also been reported to have } \\
\text { a high volume-to-surface ratio } \\
\text { which improve surface adsorption } \\
\text { that can speed up reaction kinetics } \\
\text { (Goryacheva 2016) }\end{array}$ & & Eadi et al. (2017) \\
\hline Nanoplates & Hydrothermal & $\begin{array}{l}\text { Nanoplate is a nanomaterial that has } \\
\text { plate-like structure or have two- } \\
\text { dimensional nanostructures (2D) } \\
\text { (Peng et al. 2017) }\end{array}$ & & Tan et al. (2015) \\
\hline
\end{tabular}


Table 2 (continued)

\begin{tabular}{lll}
\hline Nanomaterial & Method of Synthesis & Description \\
\hline Nanorods & Sol-gel & Nanorods are nanostructures that \\
& have rod-like shape. Nanorods \\
& have one dimension outside the \\
& nanoscale. Nanorods have unique \\
& advantage over other one dimen- \\
& sion nanostructure due to the fact \\
& that it can be made from most ele- \\
& ments (metals and nonmetals) and \\
& compounds, and simple synthetic \\
& methods compared to nanotubes \\
& and nanowires (Ghassan et al. \\
& 2019) \\
& A nanotripod is a nanomaterial that \\
& is like a portable tee-legged frame \\
& or stand with a two-dimensional \\
& nanostructure with planar arms that \\
& appear as rectangular nanoplates \\
& (Al-Sarraf et al. 2018). Zinc tripod \\
Nanotripods a two-dimensional (2D) nano- & structure
\end{tabular}

ing the preparation (Chitha et al. 2015; Swaroop and Somashekarappa 2014). This is because solution $\mathrm{pH}$ alters the electrical charge of molecules and such alteration will affect their reduction (Hasan et al. 2018). During the synthesis of $\mathrm{ZnO}$ in an acidic medium $\left(\mathrm{pH}^{<} 7\right)$, the amount of hydroxyl ions $\left(\mathrm{OH}^{-}\right)$is usually low in the solution which hinders hydrolysis and condensation processes, leading to the smaller aggregates at the end of poly-condensation process (Tourné-Péteilh et al. 2018). The decrease in the crystallite size of the zinc nanoparticle in an acidic medium was attributed to the preferential corrosion of the $\mathrm{ZnO}$ crystal structure (Rafaie et al. 2014). At the $\mathrm{pH}$ of 7 (neutral), the hydrogen ion $\left(\mathrm{H}^{+}\right)$and the hydroxyl ion $\left(\mathrm{OH}^{-}\right)$ concentrations are equal, therefore, making the solution having little or no influence at the interfaces of zinc oxide crystals (Mohammadi and Ghasemi 2018). When the $\mathrm{pH}$ of the reaction mixture is greater than 7 , the number of $\mathrm{OH}^{-}$ions is usually high causing strong attraction between the positively charged $\mathrm{Zn}^{+}$and $\mathrm{OH}$ ion; subsequently, increase crystallization and formation of a smaller $\mathrm{ZnO}$ nanoparticle. Under high concentration of the hydroxyl ions in a solution, intermediate products such as zinc hydroxide $\left(\mathrm{Zn}(\mathrm{OH})_{2}\right)$ (see Eq. 1) and salt-containing tetrahydroxozincate ion $\left(\left[\mathrm{Zn}(\mathrm{OH})_{4}\right]^{2-}\right)$ (see Eq. 2) are formed (Rafaie et al. 2014). The drying in the oven and calcination of the products in the furnace as shown in Eqs. (1) and (2) usually lead to the formation of zinc oxide nanoparticles of large crystallite size (Buazar et al. 2016).

The reaction mechanism of growth of $\mathrm{ZnO}$ nanoparticles with respect to variation of solution $\mathrm{pH}$ from acidic to basic region is shown in Eqs. 1-6
$\mathrm{Zn}^{2+}+2 \mathrm{OH}^{-} \leftrightarrow \mathrm{Zn}(\mathrm{OH})_{2}$

$\mathrm{Zn}(\mathrm{OH})_{2}+2 \mathrm{OH}^{-} \leftrightarrow\left[\mathrm{Zn}(\mathrm{OH})_{4}\right]^{2-}$

$\left[\mathrm{Zn}(\mathrm{OH})_{4}\right]^{2-} \leftrightarrow \mathrm{ZnO}_{2}^{2-}+2 \mathrm{H}_{2} \mathrm{O}$

$\mathrm{ZnO}_{2}^{2-}+2 \mathrm{H}_{2} \mathrm{O} \leftrightarrow \mathrm{ZnO}+2 \mathrm{OH}^{-}$

$\mathrm{ZnO}+\mathrm{OH}^{-} \leftrightarrow \mathrm{ZnOOH}^{-}$

$\mathrm{ZnOH}^{-}+\mathrm{Na}^{+} \leftrightarrow \mathrm{ZnOOH}-\mathrm{Na}$

The $\left[\mathrm{Zn}(\mathrm{OH})_{4}\right]^{2-}$ formed in Eq. (2) can also exist in the form of $\mathrm{Zn}(\mathrm{OH})^{+}, \mathrm{Zn}(\mathrm{OH})_{2}$, or $\mathrm{Zn}(\mathrm{OH})^{3-}$, depending on the process parameters, such as the concentration of the zinc ion $\left(\mathrm{Zn}^{2+}\right)$ and hydroxyl ion $\left(\mathrm{OH}^{-}\right)$ion during the chemical reaction (Purwaningsih et al. 2016). When the concentration of $\mathrm{Zn}^{2+}$ and $\mathrm{OH}^{-}$reaches the super-saturation degree, $\mathrm{ZnO}$ nuclei are formed based on reaction (4) (Osman and Mustafa 2015). The previous findings showed that the $\mathrm{pH}$ of the reaction mixture influenced the crystallite size and the morphology of zinc oxide nanoparticles. Researchers such as Ogbomida et al. (2018) reported the synthesis of $\mathrm{ZnO}$ nanoparticles via sol-gel method using $\mathrm{Zn}\left(\mathrm{CH}_{3} \mathrm{COO}\right)_{2} \cdot 2 \mathrm{H}_{2} \mathrm{O}$ and $\mathrm{NaOH}$ as starting materials. The mixture was stirred for $2 \mathrm{~h}$ and subsequently dried for $1 \mathrm{~h}$. $\mathrm{ZnO}$ nanoparticles produced were characterized using XRD, SEM, and UV-visible/diffuse reflectance spectroscopy and the calculated crystallite sizes $49.98 \mathrm{~nm}, 48.31 \mathrm{~nm}, 38.32 \mathrm{~nm}$, and $36.65 \mathrm{~nm}$ for the 
solution $\mathrm{pH}$ of $8,9,10$ and 11 , respectively. The authors found that the $\mathrm{ZnO}$ nanoparticles formed were mostly spherical in shape with an optimum solution $\mathrm{pH}$ of 9 . On the contrary, Ikono et al. (2012) employed $\mathrm{Zn}\left(\mathrm{CH}_{3} \mathrm{COOH}\right)_{2} \cdot 0.2 \mathrm{H}_{2} \mathrm{O}$ as a precursor, $\mathrm{NaOH}$ (precipitating agent) and ethanol solutions to prepare $\mathrm{ZnO}$ nanoparticles via sol-gel. The mixture was stirred for $2 \mathrm{~h}$ at $25^{\circ} \mathrm{C}$ after which the precipitates were washed and dried for $15 \mathrm{~min}$ at $80{ }^{\circ} \mathrm{C}$ and the size of the crystals formed was directly proportional to the solution $\mathrm{pH}$. The crystallite size increases from 10.94, 17.44, and 38.27 to $74.04 \mathrm{~nm}$ with a corresponding increase in the solution $\mathrm{pH}$ from $7,8,10$, and 12 , respectively. More so, the mineralogical phase of the prepared $\mathrm{ZnO}$ nanoparticles was examined using XRD and the authors observed that as the solution $\mathrm{pH}$ increases from 7, 8, 10, and 12, the purity of $\mathrm{ZnO}$ nanoparticles also increases and the percentage yield increased from $42.9 \%, 62.2 \%, 64.7 \%$, to $100 \%$, respectively. The differences in the crystallite size were linked to the reaction conditions used during the synthesis of the $\mathrm{ZnO}$ nanoparticle. In addition, Goryacheva (2016) demonstrated the green synthesis of $\mathrm{ZnO}$ nanoparticles using an aqueous extract of Citrus aurantifolia as a stabilizer and zinc nitrate as zinc salt precursor. The synthesis was carried out at $90{ }^{\circ} \mathrm{C}$ at $\mathrm{pH} 5,7$, and 9 , respectively. The precipitates formed were washed, dried and annealed in air at $300{ }^{\circ} \mathrm{C}$ yielding nanorods with a crystallite size of $100 \mathrm{~nm}$. XRD and SEM analysis confirmed the formation of pure hexagonal wurtzite $\mathrm{ZnO}$ nanostructure of different shapes irrespective of solution $\mathrm{pH}$. The authors reported spherical shape at $\mathrm{pH} 5$ and nanorods at $\mathrm{pH}$ of 7 and 9 , respectively. The increase in particle size and change in the morphology of the $\mathrm{ZnO}$ nanoparticles synthesized at the $\mathrm{pH}$ of 5,7 , and 9 further suggest that solution $\mathrm{pH}$ plays an important role in the crystallite size and morphology of $\mathrm{ZnO}$. The results and other research findings carried out by different workers on the effect of solution $\mathrm{pH}$ on the crystallite size and morphology on the synthesis of $\mathrm{ZnO}$ nanoparticles are summarized in Table 3 as follows.

Table 3 shows the result of analysis from different researchers due to variation of solution $\mathrm{pH}$. The results revealed that the solution $\mathrm{pH}$ plays an important role during the synthesis of $\mathrm{ZnO}$ nanoparticle. The $\mathrm{ZnO}$ nanoparticles synthesized at lower solution $\mathrm{pH}$ (acidic medium) had a smaller crystallite size irrespective of the method and the reaction conditions compared to the neutral and basic medium. This is an indication that the acidic medium affects the $\mathrm{ZnO}$ crystal structure leading to the formation of smaller crystallite sizes. At a higher solution $\mathrm{pH}$, a different trend was observed by different authors as shown in Table 3 due to the formation of an intermediate compound, which allows the formation of larger crystallite size. Generally different morphologies of $\mathrm{ZnO}$ nanoparticles were observed at different solution $\mathrm{pH}$ and the crystallite size is a function of solution $\mathrm{pH}$.

\section{Reaction temperature}

The physical methods mostly employed to synthesize nanoparticles require a higher temperature above $350^{\circ} \mathrm{C}$, while chemical route used for the synthesis of nanoparticles can be carried out at room temperature (Kvitek et al. 2016). The chemical method is the easiest way to synthesize $\mathrm{ZnO}$ nanoparticles (Ul-Haq et al. 2017). It has been reported that higher temperature resulted to increase in reaction rate causing rapid consumption of metal ion and hence formation of nanoparticle of a smaller size (Kumari et al. 2016; Saxena et al. 2016). On the contrary, another researcher reported a smaller size of $\mathrm{ZnO}$ nanoparticle even at a lower temperature (Pelicano et al. 2016). However, a study by Liu et al. (2020) observed that reaction temperature played critical role in the actual crystallite size of nanoparticles so also the concentration of metal salt precursors. The authors found that low concentration of the precursors often leads to the formation of smaller crystalline size either at a lower or higher temperature, due to the competition between nucleation and growth processes. The research by Pushpanathan et al. (2012a) showed a reduction of particle size from 26 to $17 \mathrm{~nm}$ when the temperature of the reaction medium was increased from ambient temperature to $50{ }^{\circ} \mathrm{C}$. The synthesized $\mathrm{ZnO}$ nanoparticles were characterized by SEM, XRD, and UV-visible spectrophotometer. From their result, it was noticed that an increase in reaction temperature resulted to a quick reduction of $\mathrm{Zn}^{+}$ions and subsequent formation of $\mathrm{ZnO}$ nanoparticles with a smaller crystallite size. It was also suggested that synthesis of $\mathrm{ZnO}$ nanoparticles carried out at lower temperature can also lead to formation of smaller crystallite sizes while at higher temperature nucleation was more favoured. Research by Khan et al. (2014) revealed that employing zinc acetate dihydrate, $\mathrm{NaOH}$ and cetyltrimethylammonium bromide (CTAB) as precursors produced flowershaped like $\mathrm{ZnO}$ nanoparticle at different reaction temperatures $\left(25^{\circ} \mathrm{C}, 35^{\circ} \mathrm{C}, 55^{\circ} \mathrm{C}\right.$, and $\left.75^{\circ} \mathrm{C}\right)$. The synthesized $\mathrm{ZnO}$ nanoparticles were examined using XRD, SEM, EDS, and UV-visible spectrophotometer. The authors revealed average crystallite sizes to be $23.7 \mathrm{~nm}, 82.5 \mathrm{~nm}, 69.6 \mathrm{~nm}$, and $88.8 \mathrm{~nm}$ for $\mathrm{ZnO}$ nanoparticles prepared at $25^{\circ} \mathrm{C}, 35^{\circ} \mathrm{C}$, $55^{\circ} \mathrm{C}$, and $75^{\circ} \mathrm{C}$, respectively. The increase in the crystallite size of the $\mathrm{ZnO}$ nanoparticle in a solution as the temperature increases was attributed to two phenomena, namely Oswald ripening and oriented attachment as shown in Fig. 2. The SEM results showed the existence of two types of flower petal morphologies (slender needle-like and wide-arrowlike). The slender needle-like petals were found in excess at lower temperatures compared to the large arrow-like petals in the different flower bunches of the $\mathrm{ZnO}$ colonies. These observations suggested that the temperature exerted great influence on the crystallite size and morphology of the $\mathrm{ZnO}$ nanoparticles. The differences as reported by the previous 


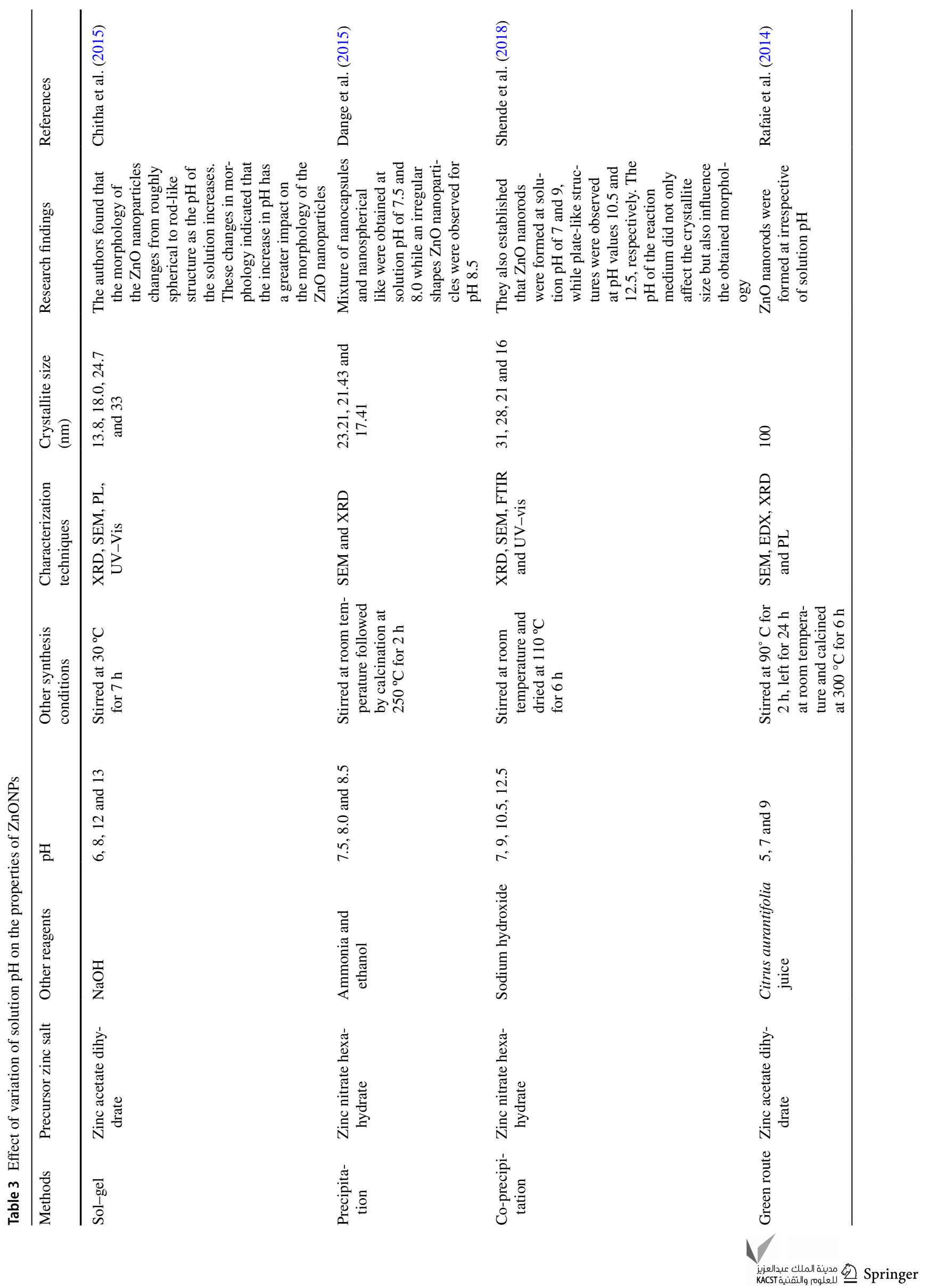




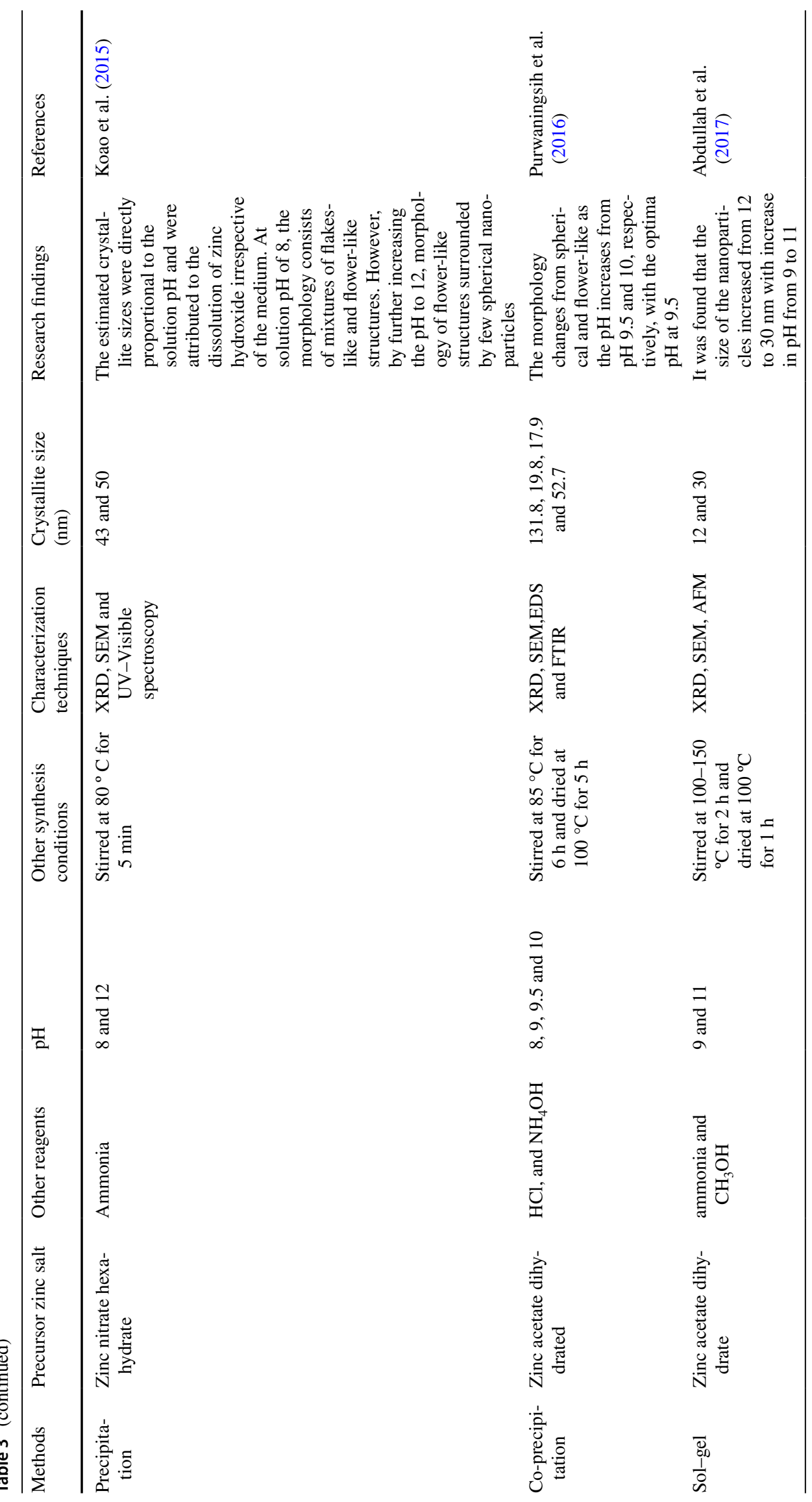




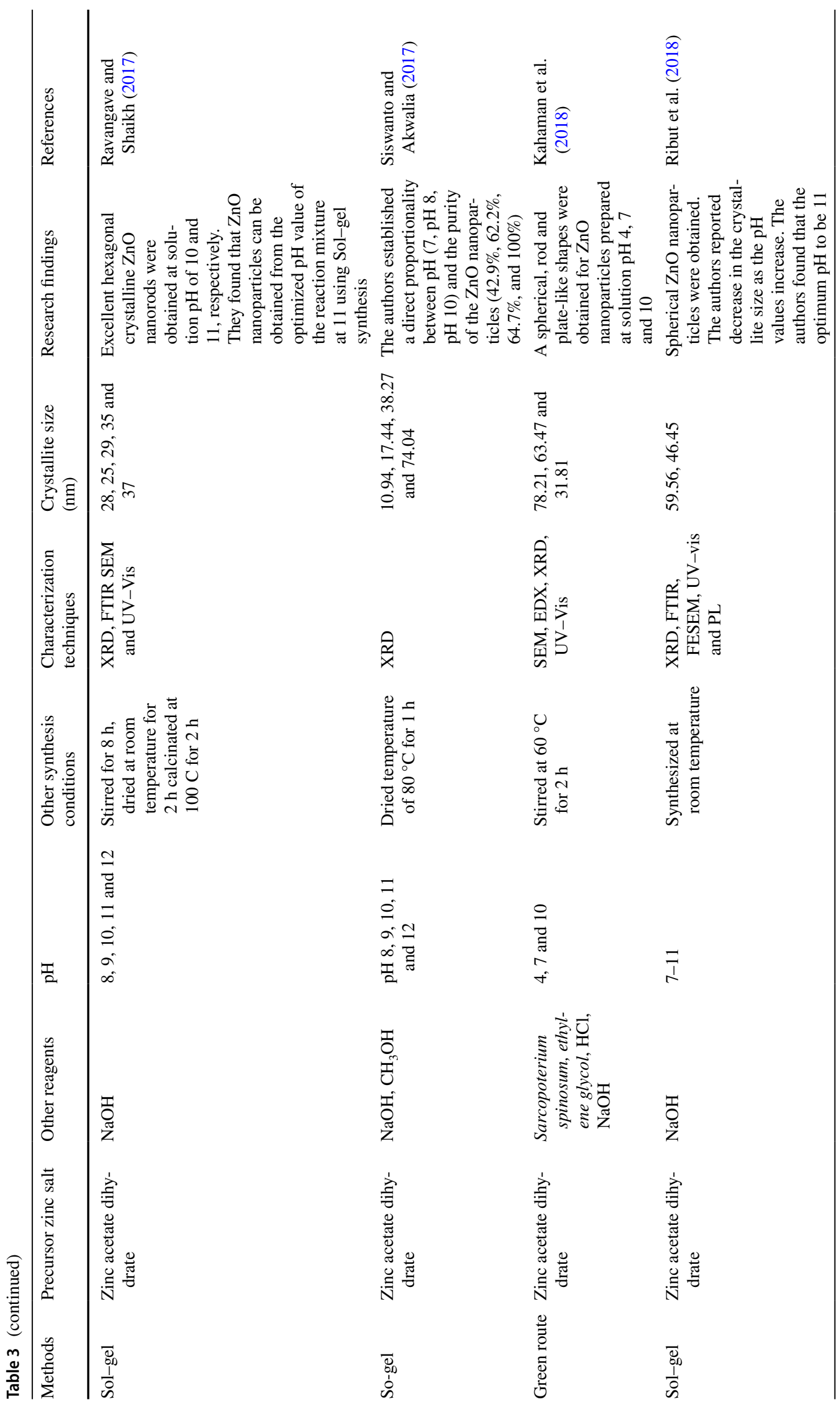




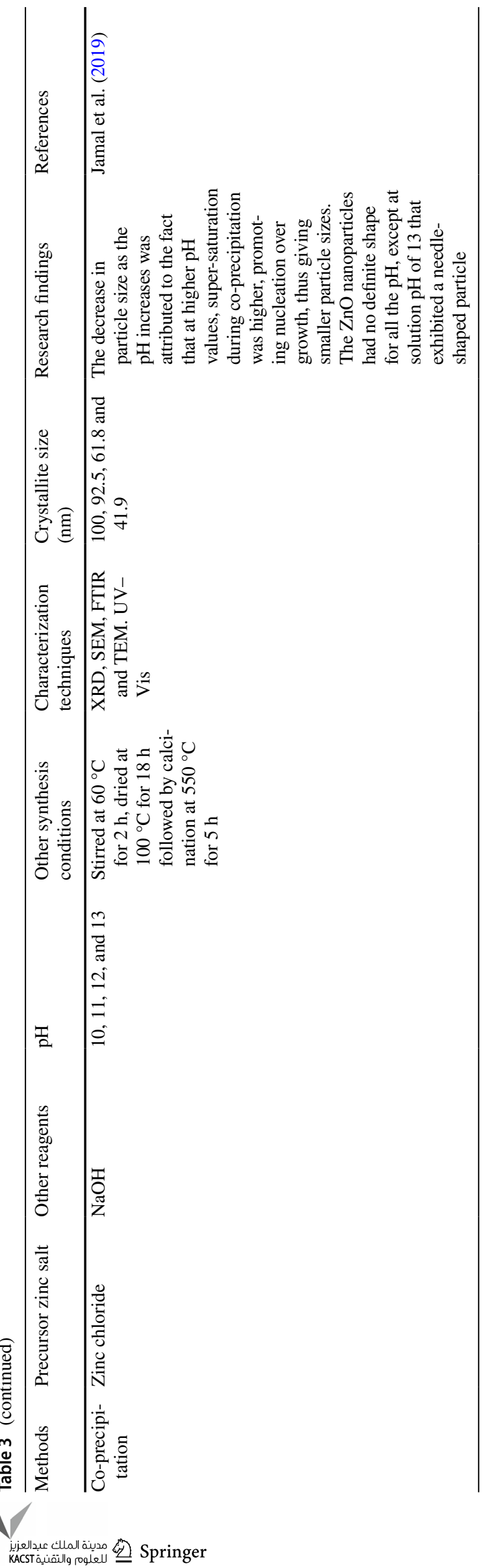

workers (Pushpanathan et al. 2012a) may be due to the differences in synthesis methods and the nature of capping agents used. Similarly, Manzoor et al. (2015) reported the synthesis of $\mathrm{ZnO}$ nanoparticles via co-precipitation method using zinc acetate with potassium hydroxide and ethanol as precursors. The mixture was stirred for $1.3 \mathrm{~h}$ under the influence of different synthesis temperature from $65{ }^{\circ} \mathrm{C}$, $70{ }^{\circ} \mathrm{C}$ to $75^{\circ} \mathrm{C}$. The final product was dried in the oven at $60{ }^{\circ} \mathrm{C}$ for $8 \mathrm{~h}$ and characterized using SEM, XRD, FTIR, and UV-visible spectrophotometer. The average crystallite sizes of the $\mathrm{ZnO}$ nanoparticle obtained at three studied temperatures were $98 \pm 43,135 \pm 77$, and $458 \pm 243 \mathrm{~nm}$, respectively. The authors established a direct relationship between the reaction temperature and crystallite sizes. Furthermore, Pelicano et al. (2016) employed precipitation method involving mixing zinc acetate dihydrate as the precursor, with ethanol and dimethyl sulfoxide; tetramethyl, ammonium hydroxide as solvent and precipitating agents to produce $\mathrm{ZnO}$ nanoparticles. The prepared $\mathrm{ZnO}$ nanoparticles were investigated by TEM, UV-visible spectrophotometer, and PL. The TEM result indicated an increase in crystallite size $(4.72 \mathrm{~nm}, 5.24 \mathrm{~nm}, 6.70$ and $7.61 \mathrm{~nm})$ as the reaction temperature increases $\left(26^{\circ} \mathrm{C}, 40{ }^{\circ} \mathrm{C}, 60^{\circ} \mathrm{C}\right.$ and $\left.80^{\circ} \mathrm{C}\right)$. The authors attributed the increment in the crystallite size to the increase in the critical particle radius and coalescence of the smaller particles to complement the growth into larger based on Ostwald ripening (for more soluble materials) and oriented fixing (for less soluble crystals) as shown in Fig. 2.

From Fig. 2, the first stage in the synthesis of $\mathrm{ZnO}$ nanoparticles is the nucleation of a solid $\mathrm{ZnO}$ crystal (E1); this is made possible via rapid precipitation reaction of a zinc salt by the precipitating agents such as sodium hydroxide, $\left(\mathrm{NH}_{4}\right)_{2} \mathrm{CO}_{3}$ and $\mathrm{NH}_{4} \mathrm{OH}$ (Herrera-Rivera et al. 2017). The second stage involved the growth of nucleus by diffusion of $\mathrm{ZnO}$ molecules from solution onto the surface of the nucleated particle (E2), followed by collision and fusion (E3) of two particles via the oriented attachment (OA) and E4 depict the Ostwald ripening (OR) which involved inter-particle growth via exchange (dissolution and diffusion) of molecules between various particles (Zhang et al. 2010). Other reported researches on the effect of reaction temperature on the crystallite size and morphology of the $\mathrm{ZnO}$ nanoparticles are summarized in Table 4.

Synthetic temperature plays a very vital role as shown in Table 4. The Table revealed that the crystallite size of the $\mathrm{ZnO}$ nanoparticles increases as the synthesis temperature increases except for the result reported by Indramahalakshmi (2017) who employed the green method for the synthesis of ZnONPs. This implies that the increase or decrease in the crystallite sizes of $\mathrm{ZnO}$ nanoparticles also did not only depend on the reaction temperature but also on the method of synthesis. 


\section{Calcination temperature}

Calcination involves heat-treating a material at a controlled temperature and in a controlled environment. During the calcination process, the particles fuse and enlarge its primary crystallite size (Ruys 2019). This process is called particle coarsening, a phenomenon in solid (or liquid) solutions often used for the growth of larger crystals from those of smaller size and lead to reduction in the number of smaller particles while larger particles continue to grow (see Fig. 3). The particle coarsening phenomenon occurs due to the fact that the smaller nanoparticles are less energetic and unstable compared to the well-packed nanoparticle with a large crystallite size. This process can also take place at room temperature and however can be accelerated during heating process. Different researchers have studied the effect of calcination temperature on properties of zinc oxide nanoparticle and these are reviewed as follows: (Parra and Haque 2014) synthesized $\mathrm{ZnO}$ nanoparticles via aqueous chemical route using zinc acetate dihydrate and sodium hydroxide $(\mathrm{NaOH})$ as precursor material for $15 \mathrm{~min}$ at $60{ }^{\circ} \mathrm{C}$. The $\mathrm{ZnO}$ nanoparticles synthesized were identified by XRD, SEM, EDX, AFM and UV-visible spectrophotometer. The authors reported that as the calcination temperature increases from $200{ }^{\circ} \mathrm{C}$, $400{ }^{\circ} \mathrm{C}$ to $500{ }^{\circ} \mathrm{C}$, the particle size also increases from 30 , 41, and $44 \mathrm{~nm}$, respectively. Besides, Ashaf et al. (2015) studied the effect of calcination temperature on properties of $\mathrm{ZnO}$ nanoparticles by sol-gel using zinc acetate as a precursor. The XRD results indicated the formation of pure phase hexagonal wurtzite $\mathrm{ZnO}$; however the crystallite size decreases from $(24-17 \mathrm{~nm})$ as the calcination temperature increased to $300{ }^{\circ} \mathrm{C}$. Further increase in calcination temperature to $500{ }^{\circ} \mathrm{C}$ resulted to increase in the crystallite size to
$19 \mathrm{~nm}$. Moreover, a similar trend was reported by Mallika et al. (2015) that employed sol-gel method to prepare zinc oxide nanoparticles using zinc nitric and polyvinyl alcohol (PVA) as a precursor and stabilizing agent, respectively. The authors varied the calcination temperature from $\left(400{ }^{\circ} \mathrm{C}\right.$, $500{ }^{\circ} \mathrm{C}$, and $600{ }^{\circ} \mathrm{C}$ to $700{ }^{\circ} \mathrm{C}$ ) at holding time of $1 \mathrm{~h}$. The synthesized $\mathrm{ZnO}$ nanoparticles were characterized using XRD, SEM, EDS, FTIR, and UV-visible Spectrophotometer and the average crystallite sizes were $7,23,35$, and $35 \mathrm{~nm}$. The authors found that as annealing temperatures increase, the grain growth also increases in sizes. A similar trend was observed when citric acid (CA) was used as reducing agent under the same calcination temperature and holding time. They reported an increase in the crystallite size from 13, 23, 30 , and $40 \mathrm{~nm}$. ZnO nanoparticles have been synthesized by sol-gel technique using zinc acetate dihydrate and diethanolamine as the precursor materials. The effects of calcination temperatures $\left(300{ }^{\circ} \mathrm{C}, 500{ }^{\circ} \mathrm{C}, 650{ }^{\circ} \mathrm{C}, 700{ }^{\circ} \mathrm{C}\right.$, and $\left.750{ }^{\circ} \mathrm{C}\right)$ were studied. The properties of the $\mathrm{ZnO}$ nanoparticles were examined by SEM, XRD, FTIR, and UV-visible Spectrophotometer. The XRD result according to Scherer equation indicated that the crystallite size increased with increasing calcination temperature (Kayani et al. 2015). Generally, it was found that as the calcination temperature increases, the crystallite sizes of the $\mathrm{ZnO}$ nanoparticles increase which can also affect its purity and morphology.

Furthermore, the growth of $\mathrm{ZnO}$ nanoparticle usually occurs via two mechanisms, namely oriented attachment (OA) and Ostwald repining (OR). Oriented attachment is a physical process that is important during crystallization process and involved direct self-organization of the primary nanoparticles and subsequent conversion by interface fusion to single crystals through sharing a common crystallographic
Fig. 2 Schematic of the stage wise-growth of $\mathrm{ZnO}$ nanocrystals in solution created based on the research by Layek et al. (2012) (a)
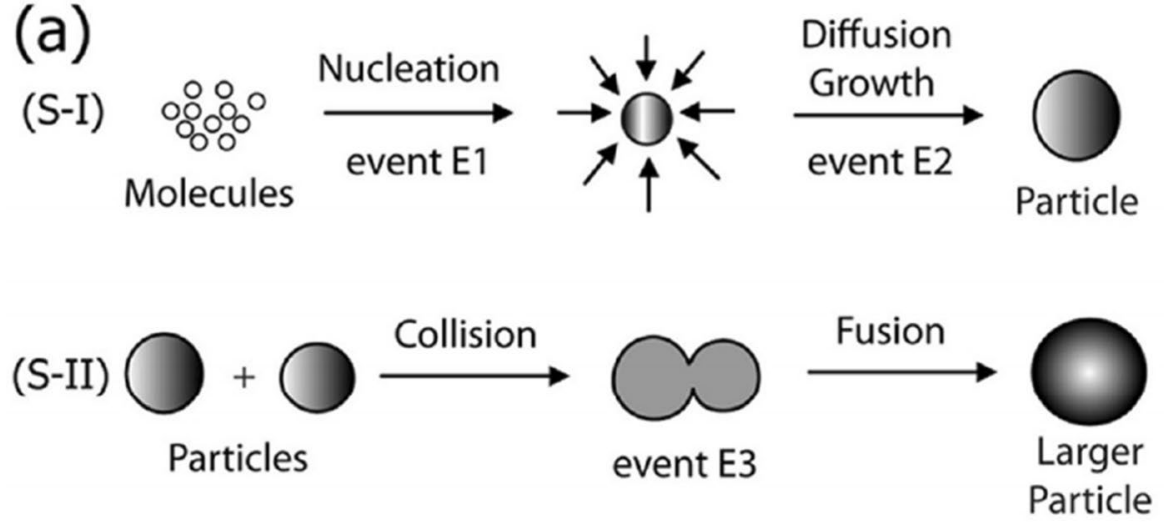
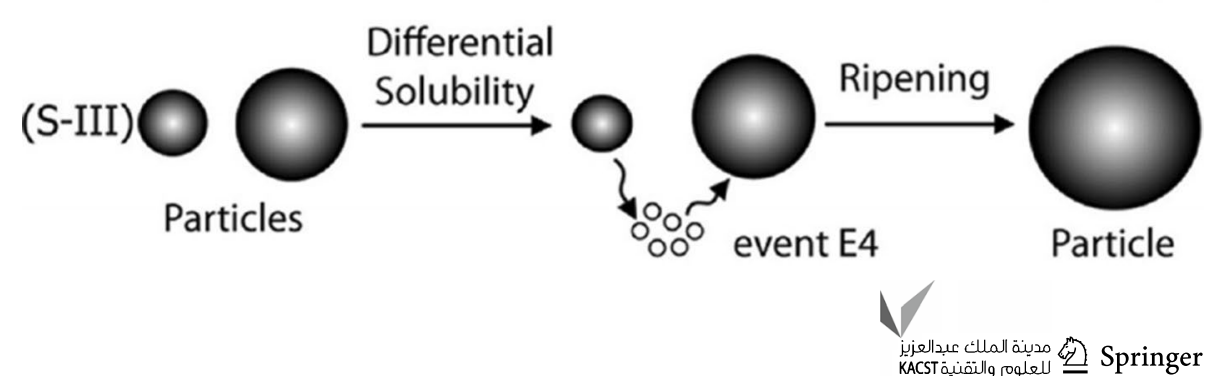


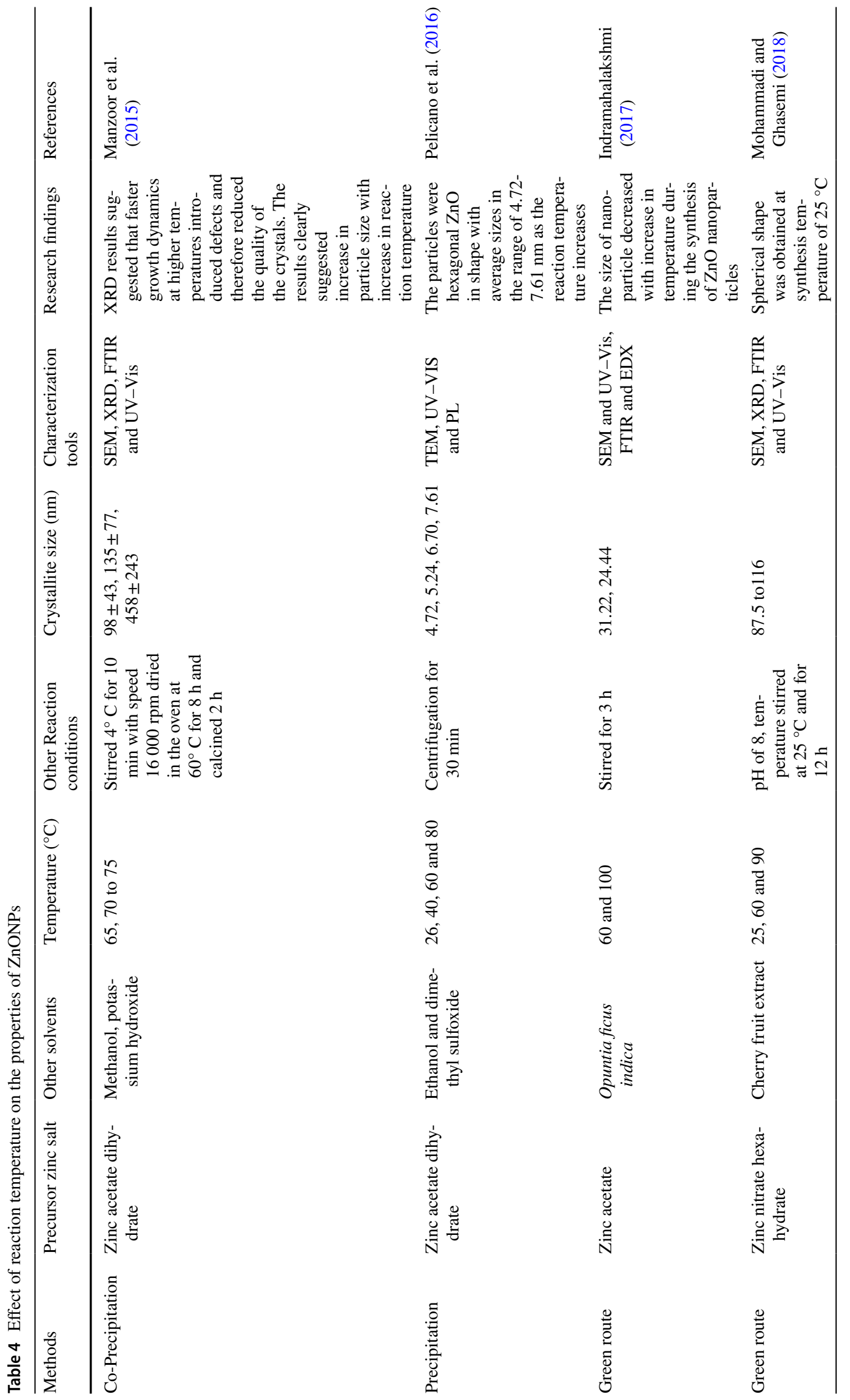




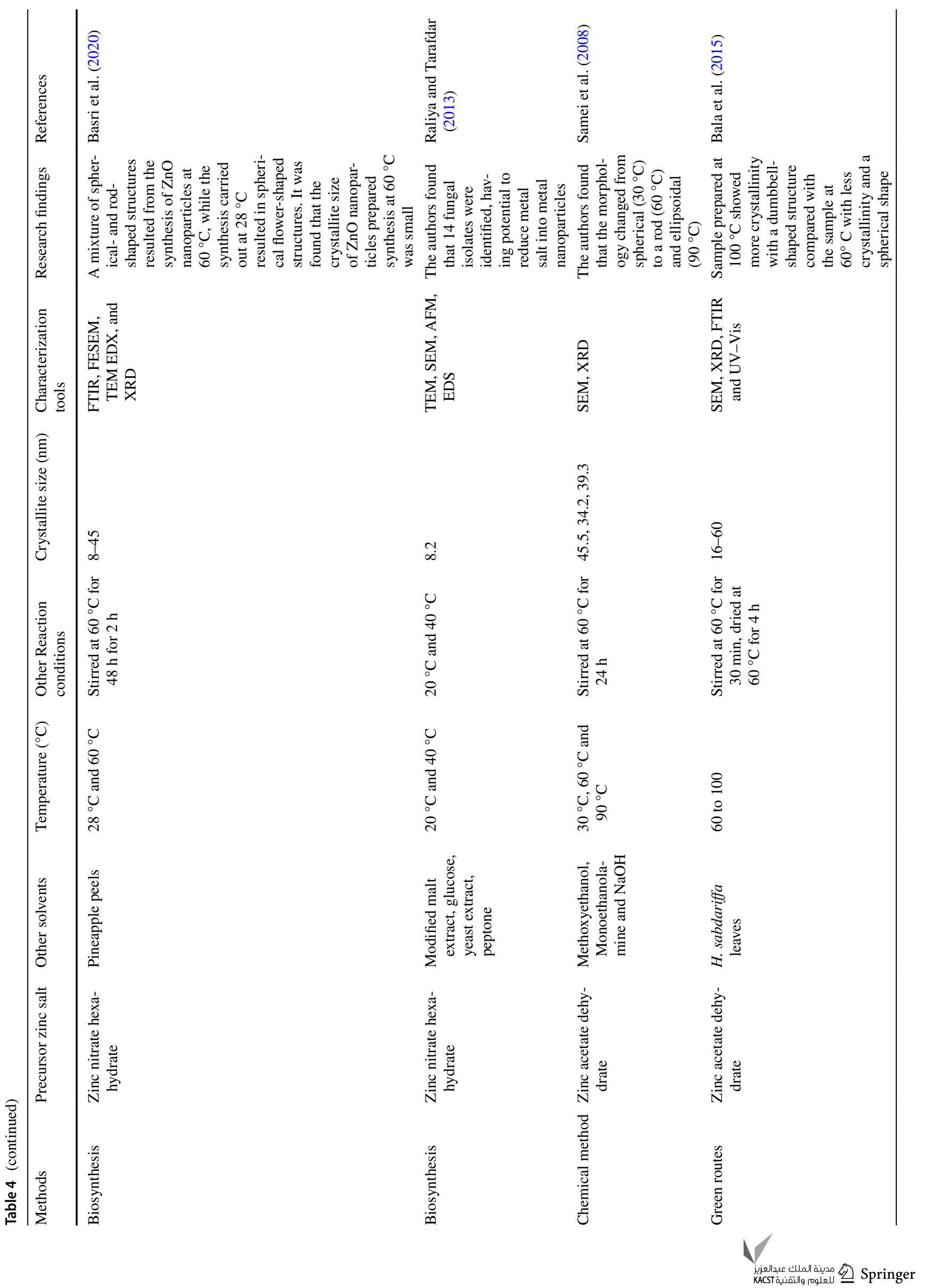




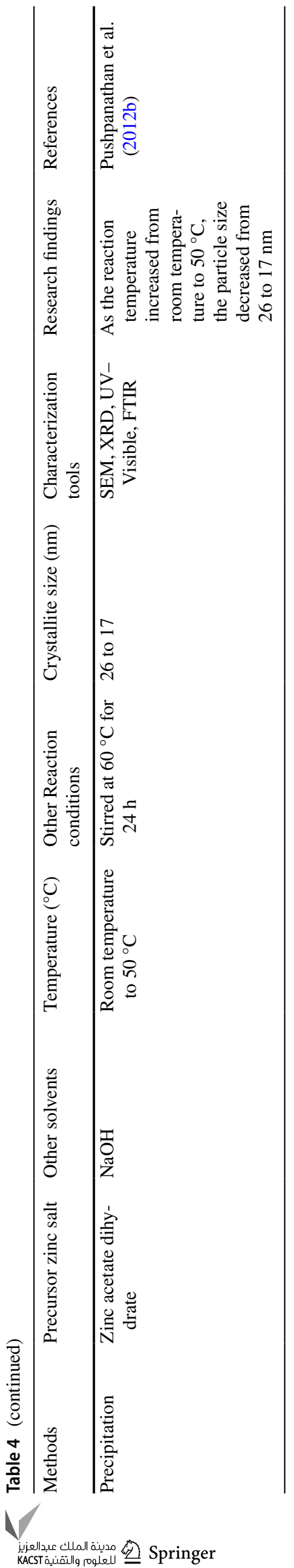

orientation (Cao et al. 2019), as illustrated in Fig. 3. Ostwald ripening involved diffusive transfer of the dispersed phase from the smaller to the larger droplets. The Ostwald Ripening occurs because larger particles are thermodynamically stronger than smaller particles. High temperature influences Ostwald ripening due to its effect on interfacial energy, coefficients of growth rate, and solubility (Westen and Groot 2018). Oriented attachment happens because the aggregation decreases the system's interphase boundary and total surface energy (Dalod et al. 2017). Previous works on the variation of calcination temperature on the properties of $\mathrm{ZnO}$ nanoparticles are summarized in Table 5.

Table 5 revealed direct relationship between calcination temperature and crystallite sizes. The higher the calcination temperature, the larger the crystallite size of the $\mathrm{ZnO}$ nanoparticles irrespective of the method, solvent and other synthesis conditions. Calcination temperatures also affect the morphology of $\mathrm{ZnO}$ nanoparticles and in most cases spherical shape of $\mathrm{ZnO}$ nanoparticles predominate.

\section{Effect of different zinc salts precursor}

The synthesis of $\mathrm{ZnO}$ nanoparticles using different zinc salts precursor such as zinc acetate $\left(\mathrm{Zn}\left(\mathrm{CH}_{3} \mathrm{COO}\right)_{2}\right.$, zinc nitrate $\left(\mathrm{Zn}\left(\mathrm{NO}_{3}\right)_{2}\right.$, zinc sulfate $\left(\mathrm{ZnSO}_{4}\right)$ and zinc chloride $\left(\mathrm{ZnCl}_{2}\right)$ has been widely investigated (Ambika and Sundararajan 2015; Ezhilarasi et al. 2016; Sierra et al. 2018). The use of different zinc salt precursors also influenced the morphological, textural and optical properties of $\mathrm{ZnO}$ nanoparticles (Mayekar et al. 2014). For instance, Gusatti et al. (2011) used different zinc salts $\left(\mathrm{ZnCl}_{2}\right.$ and $\left.\mathrm{Zn}\left(\mathrm{NO}_{3}\right)_{2} \cdot 6 \mathrm{H}_{2} \mathrm{O}\right)$ as precursors to synthesize $\mathrm{ZnO}$ nanoparticles. The mixture of zinc salts, ethanol and sodium hydroxide was stirred at $90{ }^{\circ} \mathrm{C}$ for $1 \mathrm{~h}$ and later the precipitate was washed severally and dried at $65{ }^{\circ} \mathrm{C}$ for a few hours. It was noticed that the average crystallites size of $\mathrm{ZnO}$ nanorods obtained using $\mathrm{ZnCl}_{2}$ was $23 \mathrm{~nm}$ while morphology of $\mathrm{ZnO}$ nanoparticles prepared using $\mathrm{Zn}\left(\mathrm{NO}_{3}\right)_{2} \cdot 6 \mathrm{H}_{2} \mathrm{O}$ precursor was mixture of nanoprisms and nanorods shape with an average crystallite size of $18.91 \mathrm{~nm}$. Also, Mayekar et al. (2014) utilized zinc nitrate, zinc chloride and zinc acetate and sodium hydroxide to prepare $\mathrm{ZnO}$ nanoparticles via sol-gel method. The mixture was maintained at $70{ }^{\circ} \mathrm{C}$ for $1 \mathrm{~h}$, and the gel was later dried at $65{ }^{\circ} \mathrm{C}$ for several hours. The properties of the $\mathrm{ZnO}$ nanoparticle were identified using XRD, SEM, EDX, and UV-visible spectrophotometer, and it was found that the crystallite size was $36.06 \mathrm{~nm}$ (Nanoflowers), $38.90 \mathrm{~nm}$ (Rice-like), and $39.91 \mathrm{~nm}$ (Spherical) for $\mathrm{ZnO}$ nanoparticles prepared using zinc nitrate, chloride and acetate, 
(a)

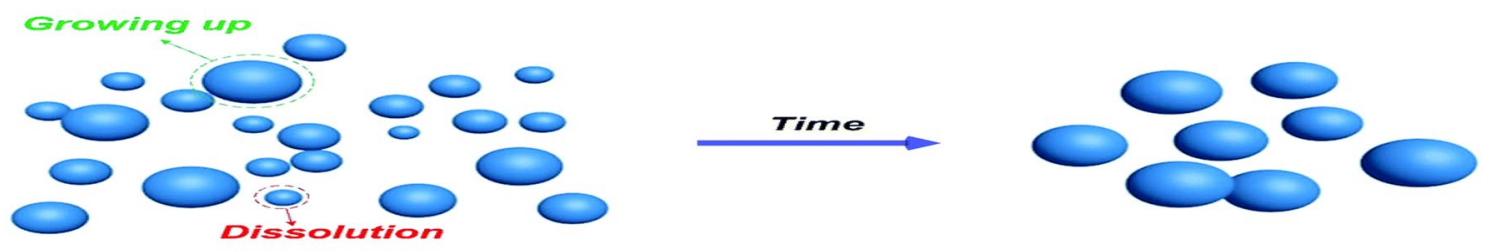

(b)

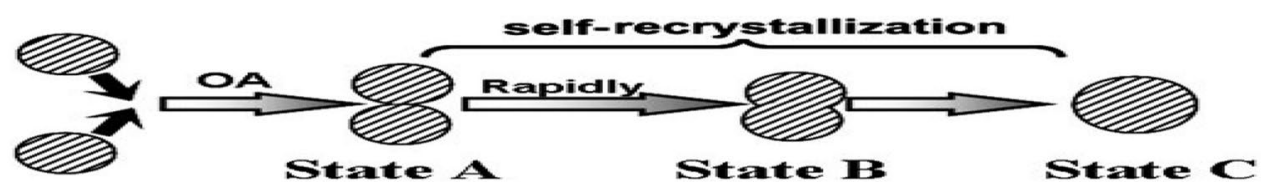

Fig. 3 Scheme of nanoparticle growth controlled by: a Ostwald ripening mechanism; $\mathbf{b}$ oriented attachment mechanism created based on the research by Kyoung-Ku et al. (2019)

respectively. The result also indicated that the $\mathrm{ZnO}$ nanoparticles synthesized using zinc acetate possessed highest purity while $\mathrm{ZnO}$ nanoparticles synthesized from using other zinc salts have similar crystallite size but different shapes. Moreover, Gusatti et al. (2011) employed hydrothermal method to synthesize $\mathrm{ZnO}$ nanoparticles using zinc nitrate, zinc acetate and zinc sulfate, sodium hydroxide as precipitating agent. The reaction was maintained at $120^{\circ} \mathrm{C}$ for $3 \mathrm{~h}$ and dried at $70^{\circ} \mathrm{C}$. The $\mathrm{ZnO}$ nanoparticles produced were characterized by XRD, SEM, and TEM. The results showed successful synthesis of $\mathrm{ZnO}$ nanoflowers $(100 \mathrm{~nm})$, nanoflakes $(125 \mathrm{~nm})$ and nanoprisms $(100 \mathrm{~nm})$ from zinc nitrate, zinc acetate and zinc sulfate, respectively (Yu and Dong 2016). This implies that different zinc salts produced different shapes of $\mathrm{ZnO}$ nanoparticles with little or no effect on the crystallite size of zinc oxide nanoparticles. Different zinc precursors such as zinc nitrate $\left(\mathrm{ZnNO}_{3}\right)$, zinc chloride $\left(\mathrm{ZnCl}_{2}\right)$, and zinc sulfate $\left(\mathrm{ZnSO}_{4}\right)$ were used to synthesize $\mathrm{ZnO}$ nanoparticles via chemical precipitation method. The authors established that the crystallite size was the same $(9.63 \mathrm{~nm})$ irrespective of the zinc salt precursor and other synthesis conditions (Stirred at room at temperature for $2 \mathrm{~h}$, dried at $80{ }^{\circ} \mathrm{C}$ for $15 \mathrm{~h}$ ). This further confirmed that the source of precursor ( $\mathrm{Zn}$ ) from different zinc salts did not have any significant effect on the crystallite size of the $\mathrm{ZnO}$ nanoparticles produced. The influence of using different zinc salt precursors for the synthesis of $\mathrm{ZnO}$ nanoparticles as reported by different researchers is summarized in Table 6.

From Table 6, it is obvious that different zinc salts have little or no effects on the crystallite size of $\mathrm{ZnO}$ nanoparticles but greatly affect its morphology. Additionally, the variation in crystallite sizes of $\mathrm{ZnO}$ nanoparticles also depends on the adopted synthesis methods and other factors.

\section{Concentration of precursors, precipitating and capping agents}

The morphology and crystallite size of $\mathrm{ZnO}$ particles often depend on the concentration of metal salt precursors precipitating, and capping agents used (Phan and Nguyen 2017). Thus, these factors play an important role in the synthesis of $\mathrm{ZnO}$ nanoparticles and other nanostructured materials and thus very frequently used to avoid over growth of nanomaterial (Gulati et al. 2016). Capping agent is responsible for the control of growth rate, particle size, and prevention of particle aggregation (Bakshi 2015). Moreover, it has been reported by Al-Hada et al. (2014) that the nanoparticles can be stabilized by immobilization on a support such as organic ligand shell, polymers, dendrimers, cyclodextrins, and polysaccharides (See Fig. 4). The capping agents must be stable enough and withstand enough heat to prevent aggregation of the nanoparticles at temperatures suitable for synthesis (Gulati et al. 2016). Many researchers including (Borghei et al. 2013) have reported that the synthesis of $\mathrm{ZnO}$ nanoparticles using low concentration of zinc precursor always leads to the formation of nanoparticles of smaller crystallite size. In their research, zinc acetate dihydrate and sodium hydroxide, ethanol were mixed together and the particles formed were dried at $100{ }^{\circ} \mathrm{C}$ for $5 \mathrm{~h}$ and later calcined at $250{ }^{\circ} \mathrm{C}$ for $3 \mathrm{~h}$ to obtain $\mathrm{ZnO}$ nanoparticles with crystallite size ranging 


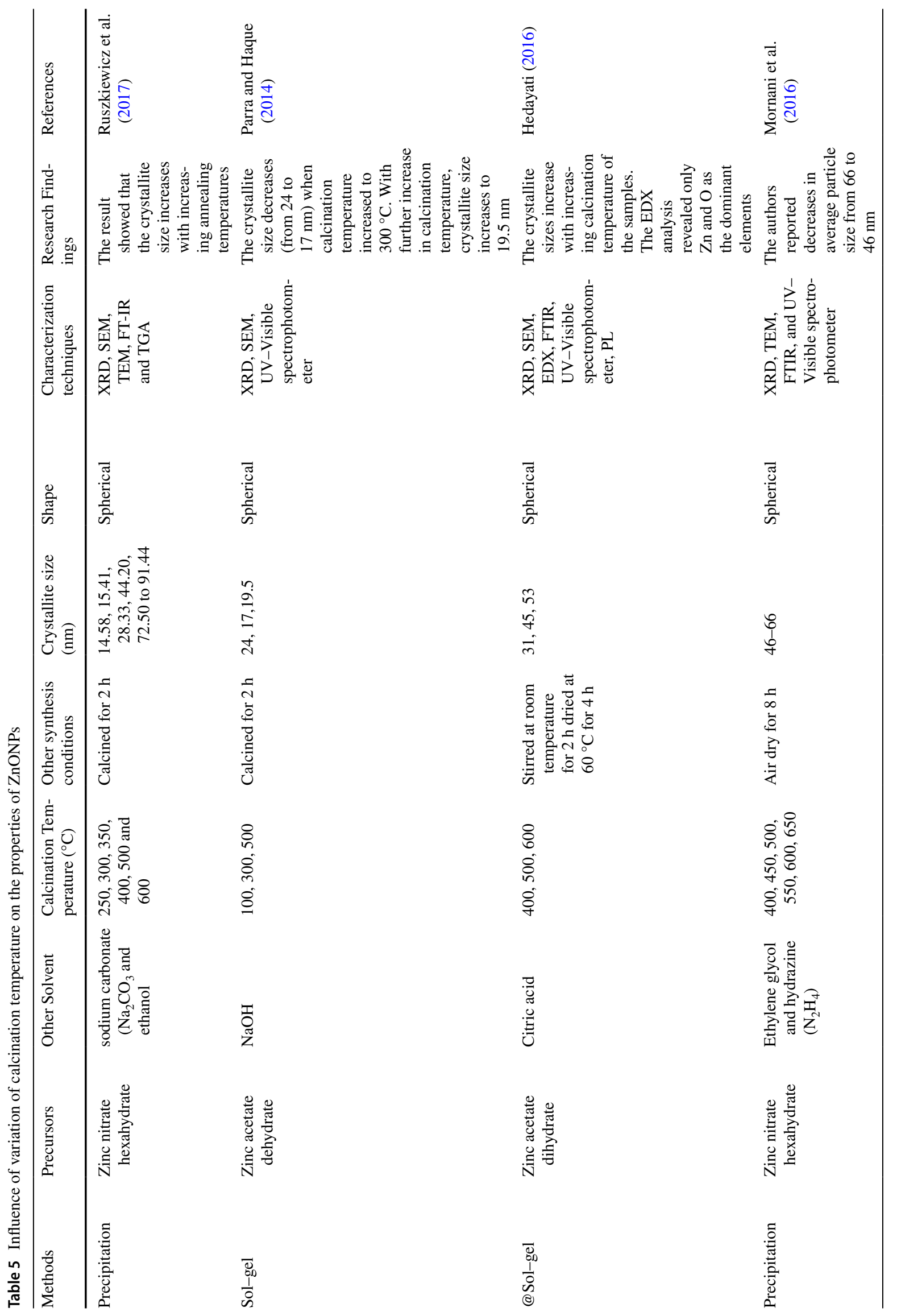




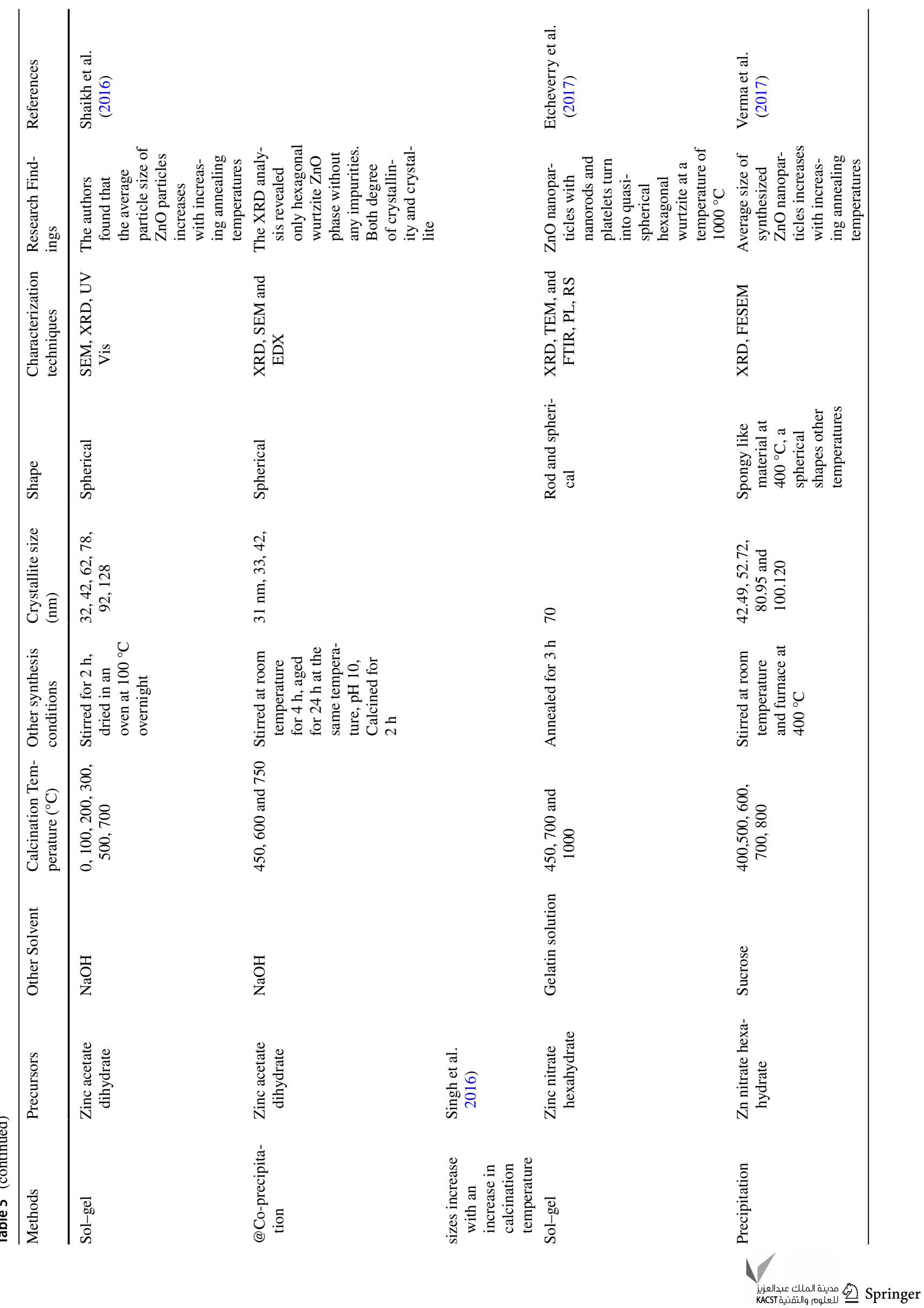




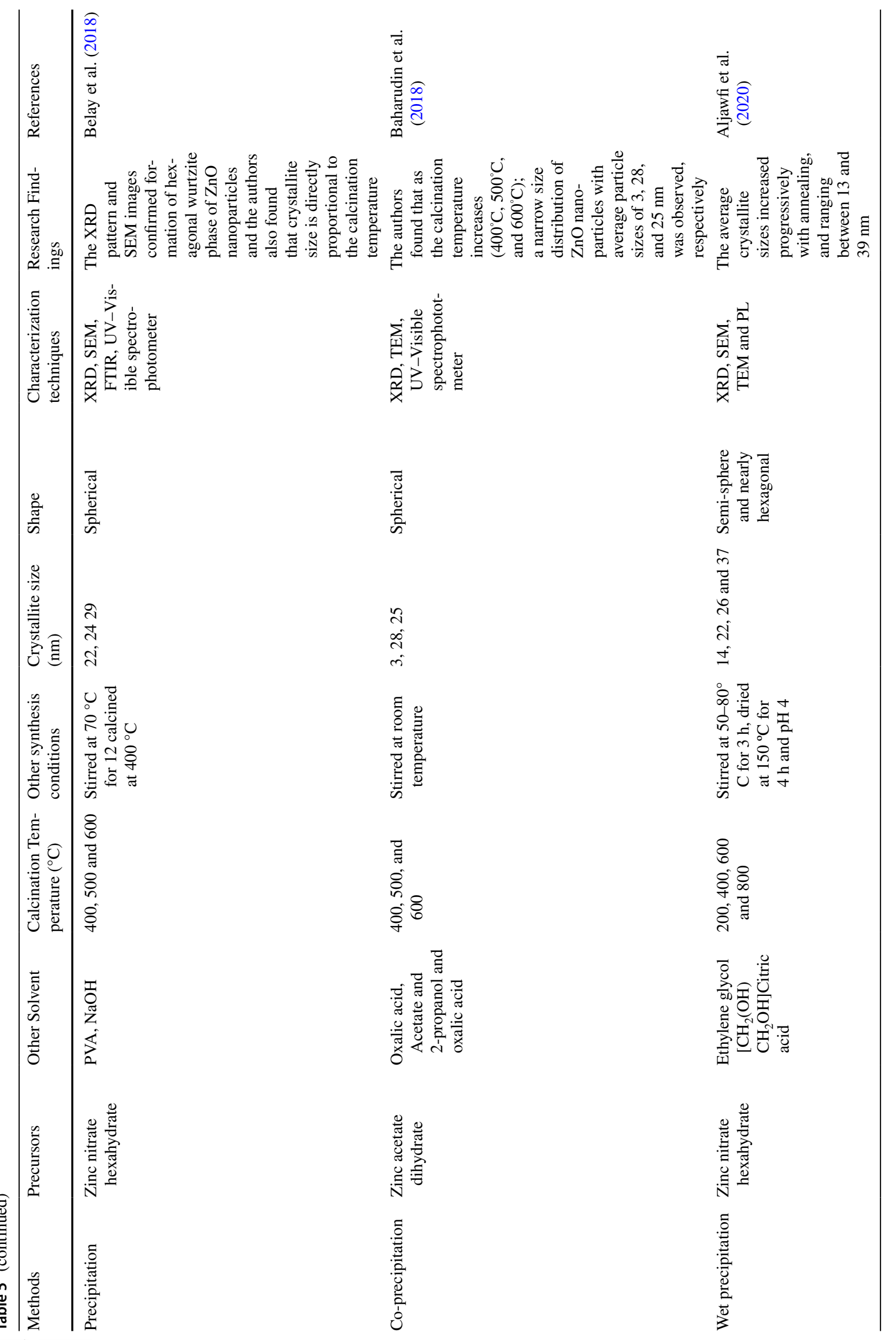


from $20,27,30$ to $36 \mathrm{~nm}$ at different mixing ratio of sodium hydroxide to zinc salts precursor $(1: 1,1: 2,1: 3$, and 1:4), respectively. Different morphologies such as Cauliflowerlike, irregularly shaped, and non-uniform were obtained by increasing the concentration ratio of the reactant raw materials. From this result, it was suggested that a higher ratio of sodium hydroxide/zinc salt precursor resulted to the formation of larger crystallites size of $\mathrm{ZnO}$. Similarly, Alami et al. (2015) employed spray pyrolysis method to prepare $\mathrm{ZnO}$ nanoparticles using different concentrations of $\mathrm{Zn}\left(\mathrm{NO}_{3}\right)_{2}$, $6 \mathrm{H}_{2} \mathrm{O}(0.05,0.1$, and to $0.2 \mathrm{M})$. The reaction was carried out at solution spray rates of $2 \mathrm{ml} / \mathrm{min}$ onto a preheated glass substrate at $500{ }^{\circ} \mathrm{C}$ for $10 \mathrm{~min}$. The crystallite sizes obtained were $9.95,27.40$, and $32.35 \mathrm{~nm}$ for $0.05,0.1$, and $0.2 \mathrm{M}$ concentration of the $\mathrm{Zn}$ salt which confirm the earlier analysis that the concentration of zinc salt greatly affects the crystallite size of the $\mathrm{ZnO}$ nanoparticles.

Table 7 contains summarized works on the effects of salt precursor, precipitating and capping agents on the nature of $\mathrm{ZnO}$ nanoparticles carried out by different researchers.

Table 7 reveals that as the concentration of the zinc salt precursors increases, the crystallite size of $\mathrm{ZnO}$ nanoparticle produced also increased. Similarly, the crystallite sizes of the zinc oxide nanoparticles also increases as the concentration of the PVA and $\mathrm{NaOH}$ increases, respectively.

\section{Reaction time}

Reaction time is the time required for completion of all steps during the synthesis of nanoparticles including the reduction and formation of nanoparticles. Reports have shown that the formation of nanoparticles starts within minutes after the addition of the metal salt precursors and increases as the reaction time increases (Chitra and Annadurai 2014). For instance, Manzoor et al. (2015) prepared ZnO nanoparticles via co-precipitation method using zinc acetate with potassium hydroxide and ethanol as precursors. The final product was dried in the oven at $60^{\circ} \mathrm{C}$ for $8 \mathrm{~h}$ and characterized using SEM, XRD, FTIR, and UV-visible spectrophotometer. The mixture was stirred for $1.3 \mathrm{~h}$ by varying the nucleation time and they found that the crystallite size of the $\mathrm{ZnO}$ nanoparticles to be 20,24, and $57 \mathrm{~nm}$ for nucleation time of $0,2,8 \mathrm{~min}$. The authors found the $\mathrm{ZnO}$ nanoparticles have a nearly spherical shape with narrow particle size distribution. From the result above, it can be deduced that the reaction time is proportional to the crystallite size of $\mathrm{ZnO}$ nanoparticles. The step by step involved on the variation of reaction time during the synthesis of $\mathrm{ZnO}$ nanoparticles is shown in Fig. 5.

The first step 1( $\left.\mathrm{T}_{1}\right)$ in Fig. 5 depicts the nucleation process (the process whereby nuclei (seeds) act as templates for crystal growth) which is the first step in the formation of $\mathrm{ZnO}$ oxide nanoparticles. This process takes place within a few seconds of the reaction (Thanh et al. 2014). Step 2 involves the growth of the nanoparticles up to an average crystallite size of $5.2 \mathrm{~nm}$ as the time increases from $\mathrm{T}_{1}$ to $\mathrm{T}_{3}$. However, it has been reported by Smolkova et al. (2017) that diffusion mechanism controlled the growth of nanoparticles during the synthesis which only occurs over a few seconds. The fourth stage is a rapid consumption of the zinc salt left in solution where the particle size increases rapidly from 5.2 to $7.7 \mathrm{~nm}$. $\mathrm{ZnO}$ nanorods have been successfully synthesized by combination of sol-gel and chemical precipitation methods using zinc acetate and sodium hydroxide as starting materials. The authors reported crystallite particle size of $33 \mathrm{~nm}, 35,38$, and $42 \mathrm{~nm}$ for different synthetic time $(2,4,6$, and $8 \mathrm{~h}$ ), respectively. The synthesized $\mathrm{ZnO}$ nanoparticles were dried in the oven at $100{ }^{\circ} \mathrm{C}$ for $2 \mathrm{~h}$ and later calcined at $100{ }^{\circ} \mathrm{C}$ for $2 \mathrm{~h}$. The prepared $\mathrm{ZnO}$ nanoparticles were characterized by XRD, FTIR, SEM, UV-visible spectrophotometer and PL and it was established that the nucleation time affects the crystallite sizes of $\mathrm{ZnO}$ nanoparticles. Their result indicates that the crystallite size increases as the nucleation time increases. Similar trends have been reported by various researchers as summarized in Table 8 .

Table 8 shows that different crystallites size is a function of nucleation time. A longer nucleation time leads to the formation of larger crystallite size. This trend observed in Table 8 may be because the particles have enough time to fuse and further fusion yielded large $\mathrm{ZnO}$.

\section{The effect of other synthesis conditions on the surface area, porosity and the crystal structure of $\mathrm{ZnO}$}

In evaluating the adsorption capacity of any adsorbent, surface area and the total pore volume play an important role. Studies have shown that the high surface area of $\mathrm{ZnO}$ nanoparticles, the greater adsorptive capacity and better the removal rate of heavy metal ions in wastewater (Shaikh and Ravangave 2015). The effects of other synthesis conditions or factors are on the textural properties, and crystals structure of $\mathrm{ZnO}$ nanoparticles is summarized in Table 9. 


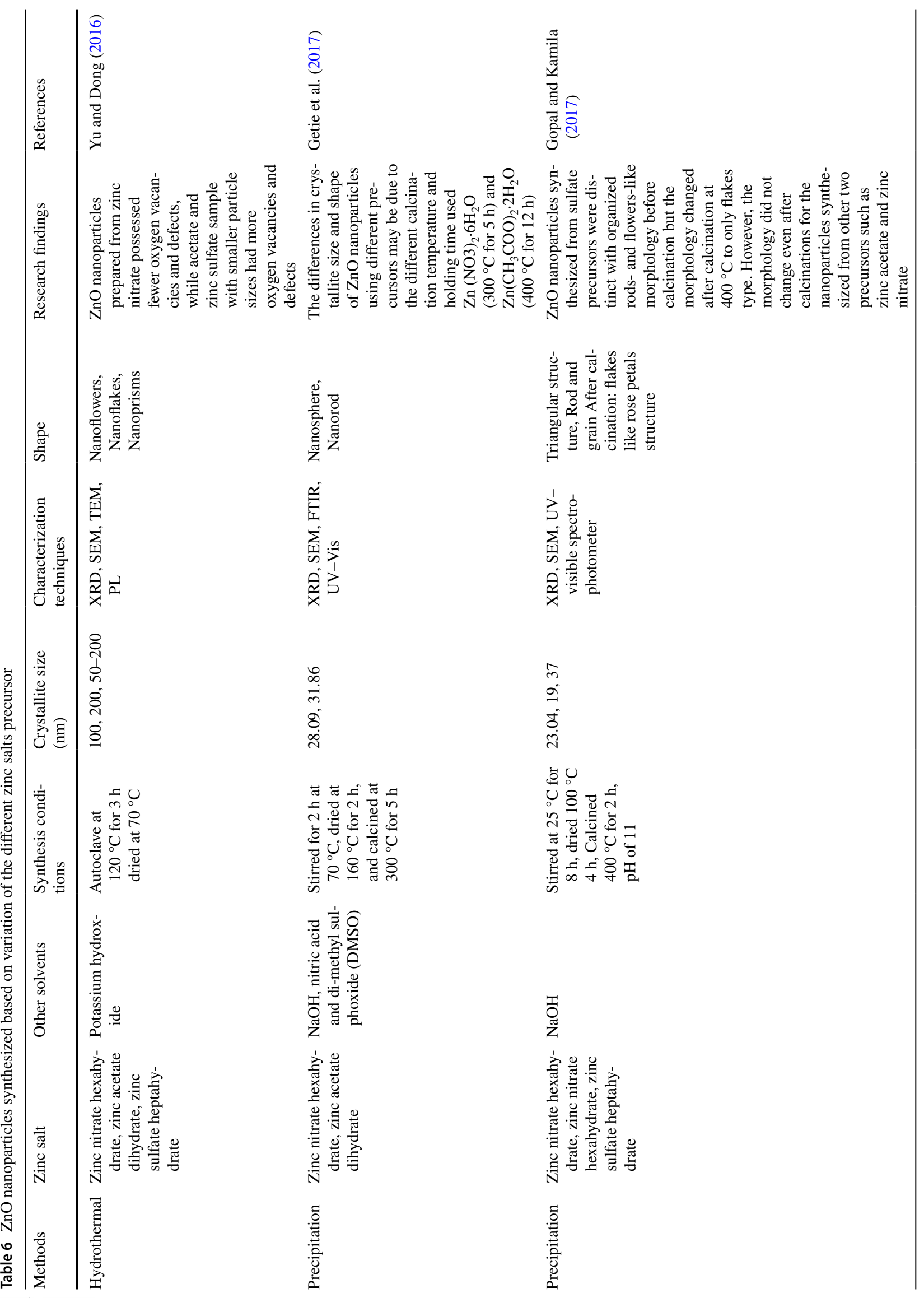




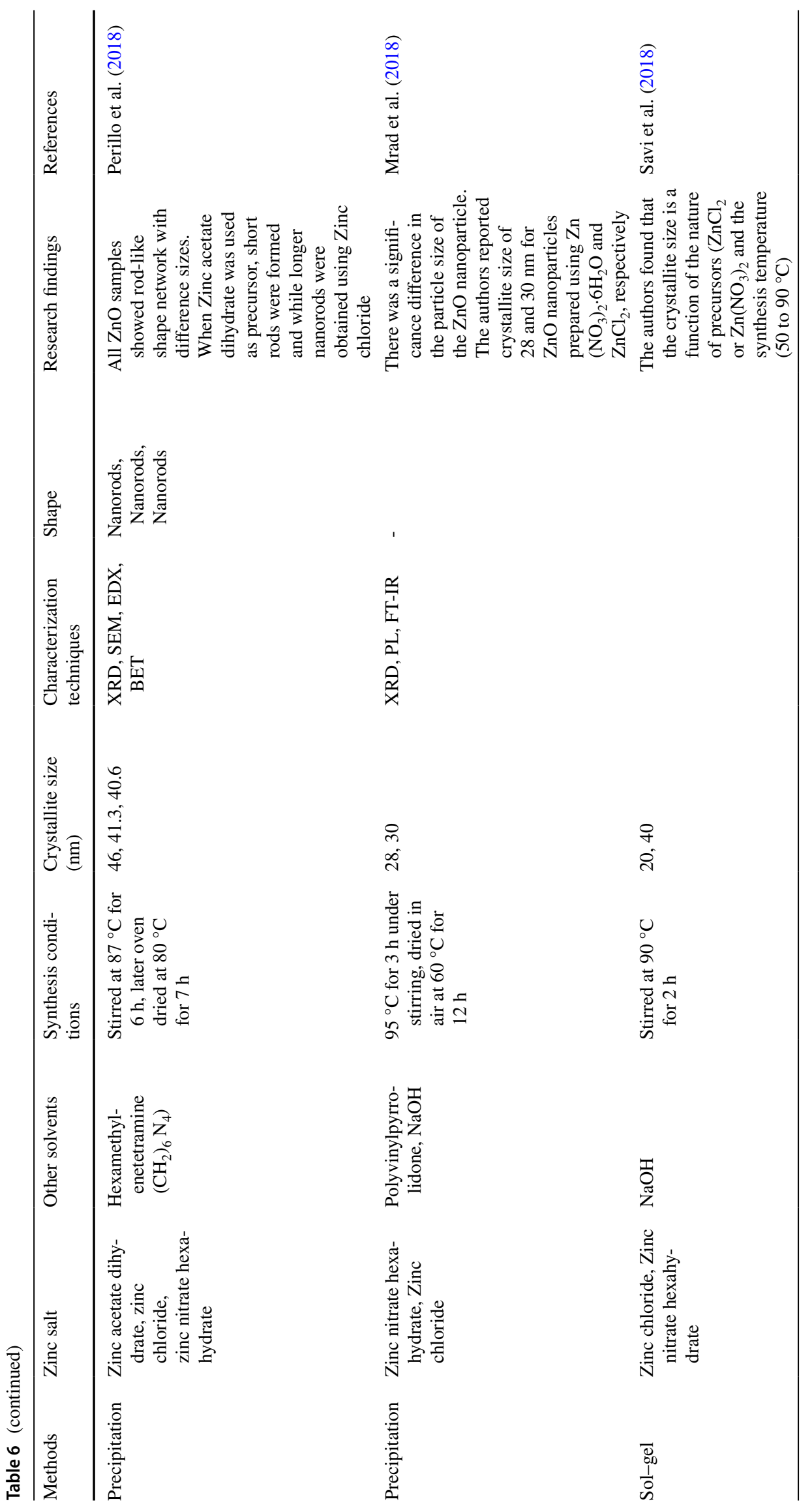




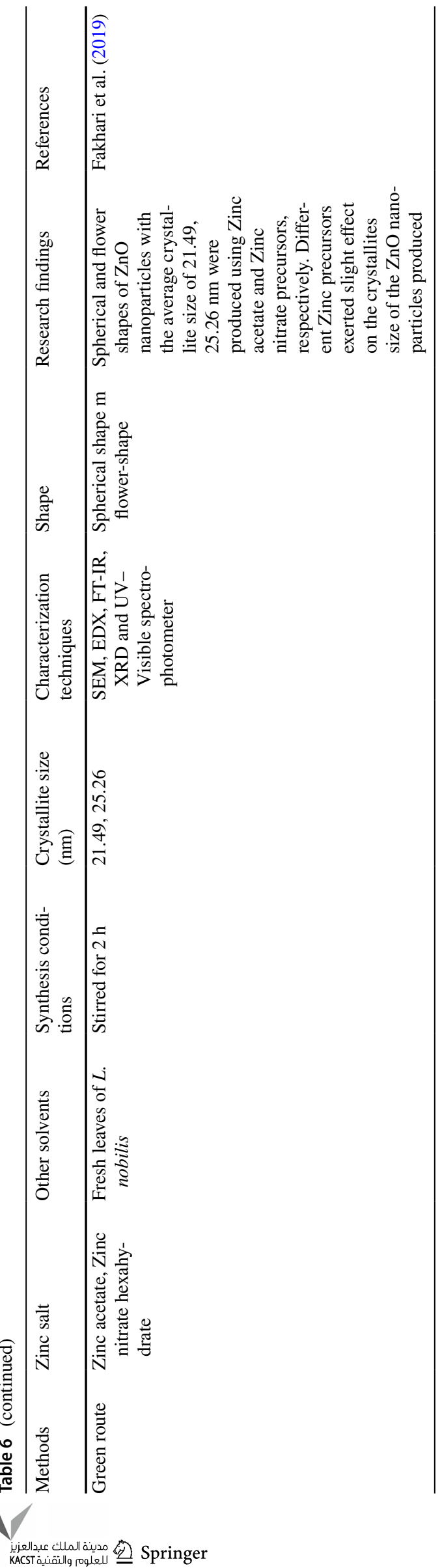

The results of different analyses summarized in Table 9 indicate that the surface area of $\mathrm{ZnO}$ nanoparticles increases so also the stirring rate and concentration of the zinc precursor, while the surface area reduces as reaction temperature and calcination temperature increase. The results also show that the change in surface area as the synthesis condition changes has little or no effect on the crystal structure of the $\mathrm{ZnO}$ nanoparticles produced. The effect of solution $\mathrm{pH}$ suggests that large surface area is obtained as the $\mathrm{pH}$ approaches a basic medium. The effect of different zinc salt did not have any major effect on the surface area of the $\mathrm{ZnO}$ nanoparticles. The next section of the review focuses on the application of $\mathrm{ZnO}$ nanoparticles for wastewater treatment.

\section{Water pollution}

Water pollution occurs when unwanted materials enter into water bodies, change its quality, and later become harmful to the environment and human health (Alrumman et al. 2016). Water is an important natural resource that needs to be protected against foreign toxic materials (Subramanian 2018). In fact, water pollution is the leading worldwide cause of deaths and diseases more war (Ladu et al. 2018). The discharge of the untreated wastewater into the water bodies has been attributed to the growing number of several diseases such as cholera, typhoid fever among others (Singh et al. 2018). It has been estimated that the world generates more than 5-10 billion tons of industrial wastes, much of which is pumped untreated into rivers, oceans, and other waterways (UNEP-Global. Marine Litter 2020). The wastewater is associated with several pollutants ranging from organic, microbial to inorganic such as heavy metals which include lead $(\mathrm{Pb})$, zinc $(\mathrm{Zn})$, nickel $(\mathrm{Ni})$, arsenic $(\mathrm{As})$, copper $(\mathrm{Cu})$, chromium $(\mathrm{Cr})$, iron $(\mathrm{Fe})$, selenium $(\mathrm{Se})$, vanadium $(\mathrm{V})$, cobalt $(\mathrm{Co})$, cadmium $(\mathrm{Cd})$, and mercury $(\mathrm{Hg})$ as a result of industrial activities (Alalwan et al. 2020). These heavy metals are recognized as a major toxic hazardous material to humans and the aquatic system (Akpor et al. 2014).

\section{Effect of heavy metals and treatment methods}

Globally, heavy metals pollution in water has caused serious health effects to humans and the ecosystem since they are non-biodegradable and highly toxic (Ogbomida et al. 
2018). These heavy metals are distributed in the environment through natural and anthropogenic activities (Engwa et al. 2016). Exposure to metals such $\mathrm{Pb}, \mathrm{Zn}, \mathrm{Ni}, \mathrm{As}, \mathrm{Cu}$, $\mathrm{Cr}, \mathrm{Fe}, \mathrm{Se}, \mathrm{V}, \mathrm{Co}, \mathrm{Cd}$, and $\mathrm{Hg}$ can affect growth and development causing mental disorder, cancer, damage the liver, kidneys, lungs, and in extreme cases, death depending on the exposure dose and time (Monisha et al. 2014). The specific effects of some of the heavy metals have been summarized (see Table10). The possible removal of these pollutants from the wastewater before the discharge to the environment has recently become the focus of many researchers owing to its negative effect on the environment. Effective wastewater treatment is a major prerequisite for a growing economy in the current era of water scarcity. Methods for removing these pollutants from wastewater include chemical precipitation, ion exchange, photocatalytic technology, coagulation, electrocoagulation, membrane bioreactor, flocculation, chemical oxidation and reduction, reverse osmosis, ultrafiltration electrodialysis, and activated carbon adsorption (Abbas et al. 2016). However, the aforementioned methods have some limitations such as sensitive operating conditions, high reagent requirement, low removal efficiency, high cost, and generation of toxic secondary pollutants (Gunatilake 2015). Among the methods used for removal of heavy metals, adsorption technique platform with nanotechnology has been recognized as the most suitable method for removal of heavy metals due to their unique properties which include, low cost, high efficiency, ease of operation, simple design, cost-effective and, regeneration potentials (Cai et al. 2019; Wołowiec et al. 2019). Furthermore, it has been reported that adsorption did not produce secondary pollutants (Gupta et al. 2014). Many materials such as activated carbon from agricultural waste chitosan, clay, polymer biopolymers, graphene-based are known for their efficiency for the removal of heavy metals (Sharma et al. 2017; Maduabuchi 2018). Many other nanoadsorbents developed include metal oxide nanoparticles such as zinc oxide, ferric oxides, magnesium oxides, titanium oxides, manganese oxides, silicon oxides, cerium oxides, and aluminum oxides nanoparticles, nanocomposites and rubber tire, multiwalled carbon nanotubes, carbon nanotubes (Ihsanullah et al. 2015; Mahmoodian et al. 2015). Among the aforementioned, metal oxides such as $\mathrm{ZnO}$ have been widely recognized as a suitable nanostructure material that can solve the deficiencies associated with many adsorbents. Zinc oxide is the most popular due to its excellent properties such as high surface area, easy removal after sorption, and pronounced selectivity of pollutants at trace concentrations, antimicrobial activities, nontoxicity, and simple synthetic methods among others metal oxide nanoparticle (Kumar et al. 2013). $\mathrm{ZnO}$ nanoparticles have been the major focus of many researchers as a new adsorbent that could be used to remove heavy metals from industrial wastewater due to its exceptional chemical and thermal resistance and others (Gupta et al. 2014).

\section{Adsorption technology}

Adsorption is a mass transfer process that involves accumulation of substances at the interface between two phases, such as liquid-solid, liquid-liquid, liquid-gas, and solid-gas interface and becomes bound by physical or chemical interaction (Girish and Murty 2017). Adsorption is an effective and inexpensive process used for the treatment of wastewater (Lata et al. 2019). The removal of pollutants usually occurs when an adsorbate in a solution comes into contact with the adsorbent, concentrates or accumulates on another surface as shown in VIII. Adsorption process is often reversible, since the adsorbents can be regenerated by desorption process (Cai et al. 2019). Adsorption can be classified into physical adsorption (physisorption) and chemical adsorption (chemisorption) and depend on the properties of both the adsorbate and the adsorbent (Ziółkowska et al. 2016). An adsorbent material must have certain important properties, such as high surface area, the distribution of pores, and the existence of the pores that have a significant influence on the form of the adsorption process, high internal volume accessible to the various target components (Kyzas and Kostoglou 2014). If the forces of attraction that exist between adsorbate and adsorbent have a physical nature, the process is called physisorption. This process is characterized by the formation of weak intermolecular forces such as van der Waals forces, reversible process, and formation of multilayer of adsorbate on the adsorbent, decrease with increase in temperature 

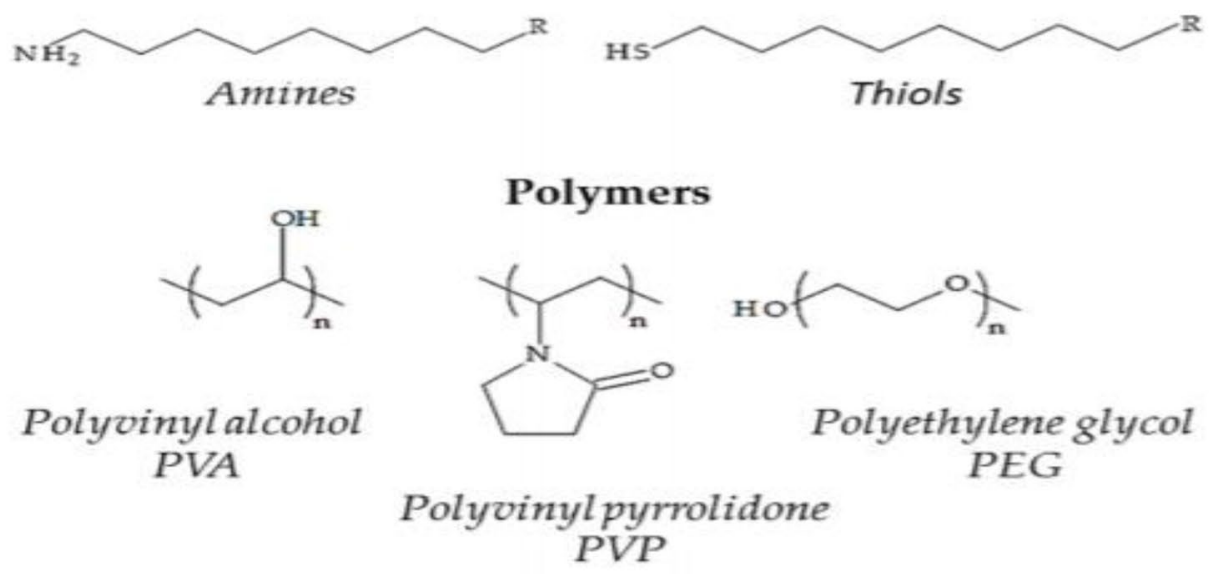

Dendrimers<smiles>NCCNC(=O)CCN(CCC(=O)NCCN)CCN(CCC(=O)NCCN)CCC(=O)NCCN</smiles>

Cyclodextrins

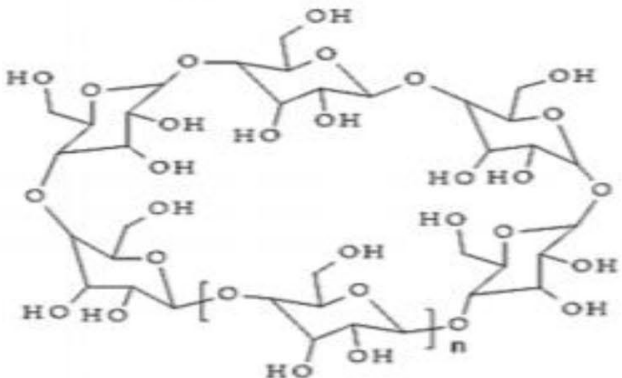

PAMAM

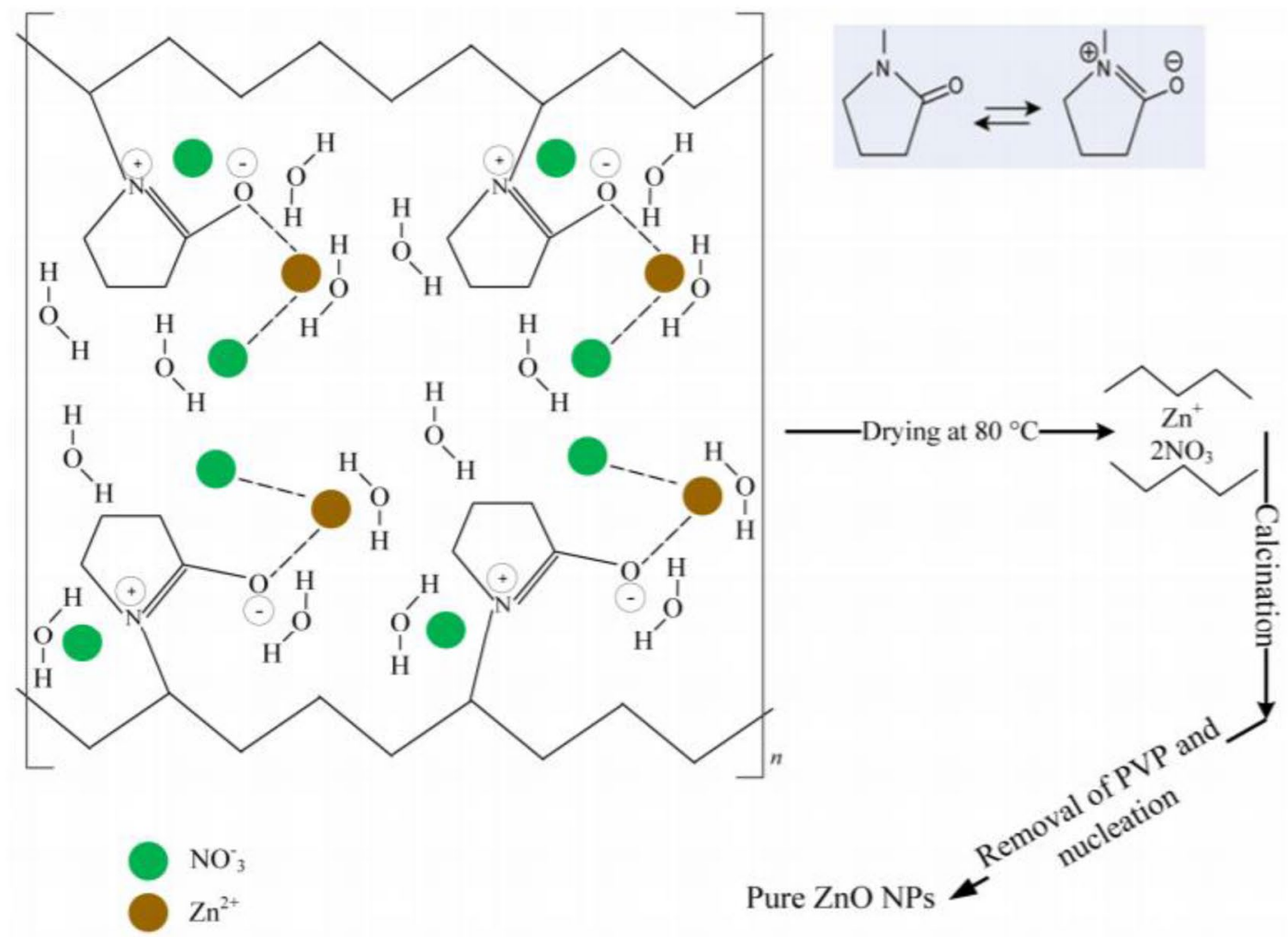


4Fig. 4 Selected capping agents used in synthesis of ZnONPs, possible mechanism of formation of $\mathrm{ZnO}$ nanoparticles using plant Extract (a) and a proposed mechanism of the interaction between zinc ions $\left(\mathrm{Zn}^{+}\right)$ and polyvinyl pyrrolidone (PVP) (b)

and has a low enthalpy of adsorption. On the other hand, if the interaction between the adsorbent and adsorbate has a chemical nature, the process is known as chemisorption, thus resulting to the formation of a strong chemical bond (Abas et al. 2013). The chemisorption process is characterized by the formation of a monolayer of adsorbate on the adsorbent, has a high enthalpy of adsorption and can take place at all temperatures and in most cases not reversible (see Fig. 6).

\section{Mechanisms of adsorption technology}

The mechanism of adsorption involves the sorption of sorbate molecules on the surface of the sorbent through molecular interactions, and diffusion of sorbate molecules from the surface into the interior of the sorbent materials, either by monolayer or multilayer (Bushra et al. 2017). Adsorption process involves the binding of metal ions by physical (van der Waals forces) or chemical (ion exchange, chelation, precipitation, binding, complexation, and reduction). Various factors such as the nature of adsorbent, temperature, dosage, adsorption time, the reaction temperature, and the surface area played an important role in the removal of heavy metals by $\mathrm{ZnO}$ nanoparticle (Iftekhar et al. 2018). The adsorption of heavy metals from wastewater using $\mathrm{ZnO}$ nanoparticles could be complex depending on the nature of capping agents used during the synthesis of $\mathrm{ZnO}$ nanoparticles, because the capping agent may contain different functional groups that may greatly influence the removal of the heavy metals through metal ion exchange, chelation, precipitation, binding, complexation, and reduction (see Fig. 7.). The adsorption process may be simple or complex depending on the number of contaminants in the aqueous matrix. There are instances where the adsorption process may contain one, two, three or more pollutants in the wastewater and in most cases serious competition for the active surface sites among the adsorbates becomes an issue. The selectivity factor for the adsorbents also comes into play and may be in the form of electrostatic repulsion (desorption) or electrostatic attraction (adsorption) between the adsorbate and adsorbents.

Physical adsorption (physisorption) is the simplest immobilization method; it occurs when the attractive forces present between adsorbate and adsorbent are weak such as van der Waals forces, hydrophobic interactions, and hydrogen bonding (Sandhyarani 2019). This process occurs readily at low temperatures and decreases with increasing temperature. Physical adsorption has been reported to have a low enthalpy of adsorption ( $<-40 \mathrm{~kJ} / \mathrm{mol})$ with a multilayer adsorbate on adsorbent (Chakraborty et al. 2009). Chemical Adsorption (chemisorption) involves a chemical reaction between the adsorbent and adsorbate and usually leads to chemical bond formation and have a higher enthalpy of adsorption in the range of 80-240 kJ/mol (Mahmoud 2015).

\section{Zinc oxide Nanoparticles as Nano-adsorbent for removal of heavy metals from aqueous matrix}

Different researchers have employed $\mathrm{ZnO}$ nanoparticles to remove heavy metals from simulated and industrial wastewater. For instance, Mahdavi et al. (2012) investigated the removal of $\mathrm{Cd}^{2+}, \mathrm{Cu}^{2+} \mathrm{Ni}^{2+}$, and $\mathrm{Pb}^{2+}$ from aqueous solutions using $\mathrm{ZnO}$ nanoparticles as an adsorbent. The XRD result in the $\mathrm{ZnO}$ nanoparticles revealed a crystallite size of $16.70 \mathrm{~nm}$ while SEM analysis confirmed the formation of rod-like shape with a crystallite size of $25 \mathrm{~nm}$. The BET analysis of the revealed specific surface area, total pore volume, and pore size of $31.20 \mathrm{~m}^{2} / \mathrm{g}, 12.09$, and $15.81 \mathrm{~nm}$, respectively. The authors found that the adsorption of the heavy metal ions increases as the $\mathrm{pH}$ of the solution increases from acidic to alkaline. It was noticed that the $\mathrm{pH}$ of the solution played an important role in the adsorption of heavy metals by nanoadsorbents. This is expected because, at lower $\mathrm{pH}$ (acidity conditions), the hydrogen ions strongly compete with heavy metal ions in the solution (Ouyang et al. 2019). Moreover, the authors also observed that an increase in the absorbent dose $(0.5$ to $5 \mathrm{~g} / \mathrm{l})$ resulted to an increase in the removal efficiency of $\mathrm{Cd}^{2+}, \mathrm{Cu}^{2+}, \mathrm{Ni}^{2+}$ and $\mathrm{Pb}^{2+}$ with $\mathrm{Pb}^{2+}$, having the highest percentage removal of $81.5 \%$ at a dosage of $5 \mathrm{mg} / \mathrm{g}$. The observed trend was attributed to the increase in the number of binding sites as 


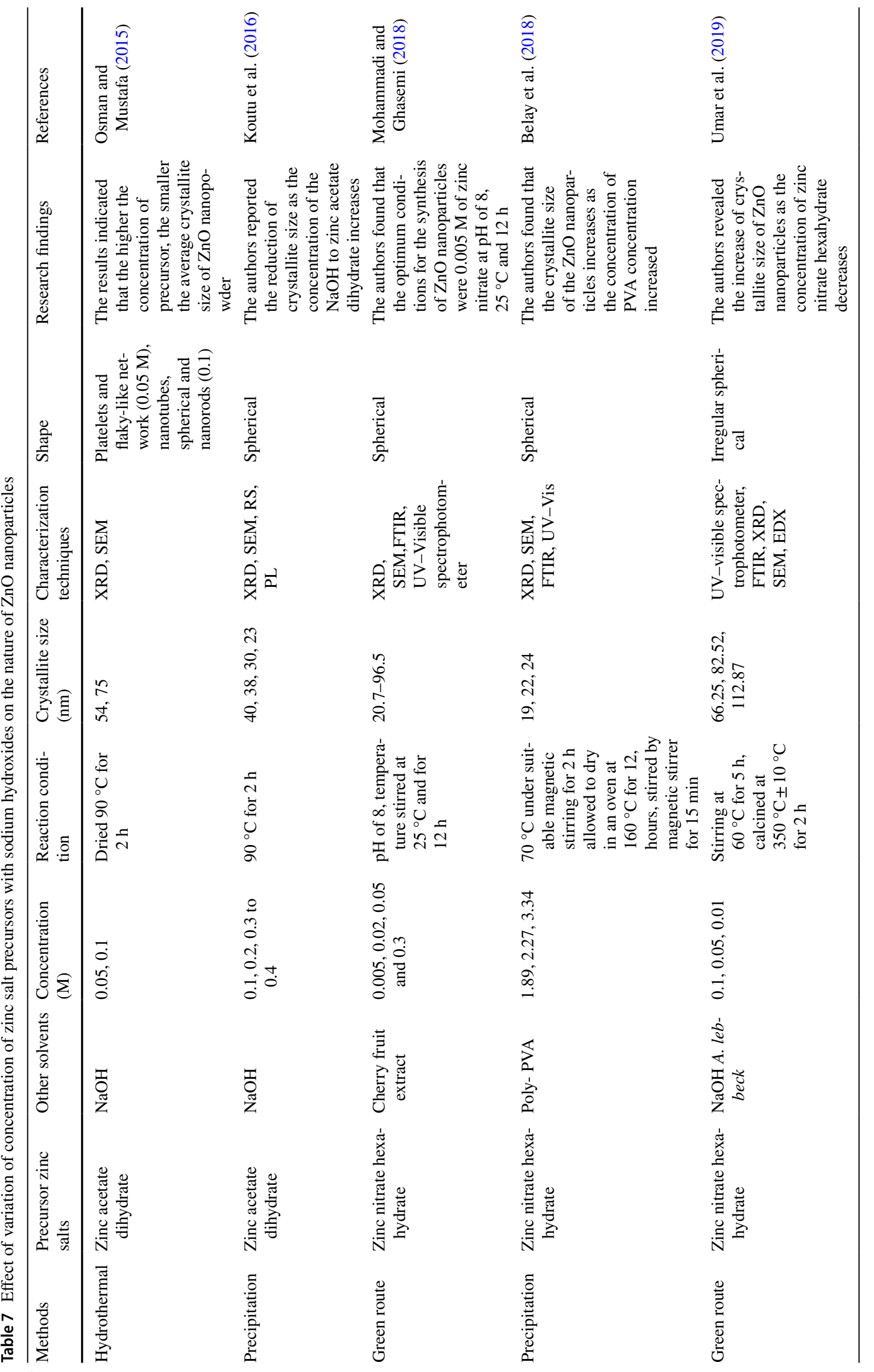


Fig. 5 Schematic illustration for effect of reaction time on the synthesis of $\mathrm{ZnO}$ nanoparticles (Polte et al. 2010)

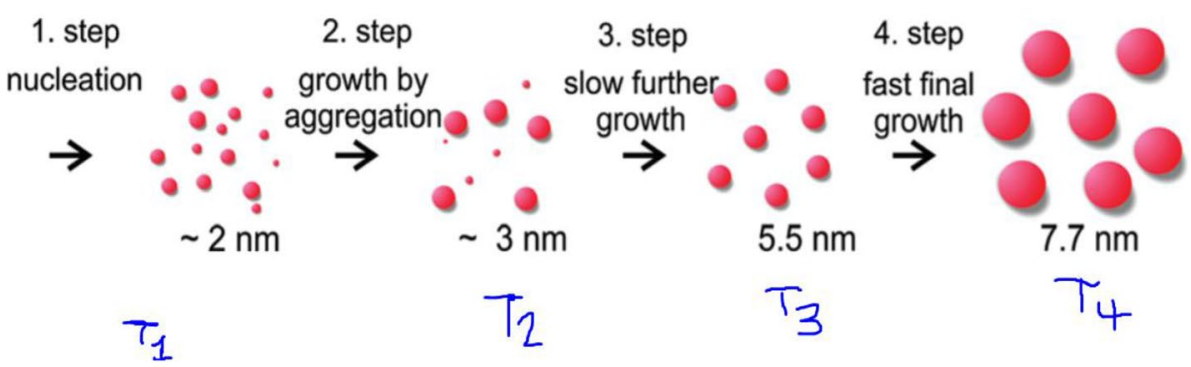

the nanoabsorbents increase (Xie et al. 2015). The maximum removal efficiency was achieved for all the four ions after $180 \mathrm{~min}$ and there was no significant increase in the removal efficiency of the metal ions after $180 \mathrm{~min}$ to $24 \mathrm{~h}$. The maximum uptake of the metal ions was reported to be $114.5 \mathrm{mg} / \mathrm{g}$. In addition, Salmani et al. (2013) reported removal efficiency of $89.6 \%$ for $\mathrm{Cd}^{2+}$ ion using $\mathrm{ZnO}$ nanoparticles. The authors found that the $\mathrm{Cd}^{2+}$ ion removal followed the pseudo-second-order and Langmuir isotherms model and the efficiency was highly sensitive to the change in $\mathrm{pH}$ and ionic strength. They also confirmed that removal efficiency increases as the $\mathrm{pH}$ of the solution increases from 4 to 7 . The result showed that the maximum removal of $\mathrm{Cd}^{2+}$ ion was achieved at lower contact time and later decrease despite increase in the contact time. This shows that the solution $\mathrm{pH}$, contact time, concentration of metal, and temperature affect the removal of metal ions using $\mathrm{ZnO}$ nanoparticle as an adsorbent. Moreover, other works done by various researchers on the application of $\mathrm{ZnO}$ nanoparticles as a nanoadsorbent for the removal of heavy metals from wastewater is presented in Table 10

Table 11 shows $\mathrm{ZnO}$ nanoparticle of different sizes and morphologies were synthesized by different methods. The result revealed that the $\mathrm{ZnO}$ nanoadsorbents show adsorptive removal efficiency between 61 and $100 \%$ with $\mathrm{ZnO}$ nanoparticle with a spherical shape has the highest $(100 \%)$ removal for $\mathrm{Cu}^{2+}$. From the Table $11, \mathrm{Bi}^{3+}$ has the lowest adsorption using spherical $\mathrm{ZnO}$ nanoparticles. The adsorptive capacities of $\mathrm{ZnO}$ nanoparticles depend majorly on several factors particularly the methods of synthesis which have direct link to the textural, morphology and optical properties of the material under review.

\section{Effect of solution pH on removal efficiency of heavy metals}

$\mathrm{pH}$ is one of the most significant control factors that directly influence removal of heavy metals during adsorption process. It can also influence the binding sites on the surface of the nanoadsorbent and also affect the degree of heavy metals ionization and chemical nature of the adsorbent (Jin et al. 2011; Duan et al. 2016). For instance, Degen and Kosec (2000) studied the effect of $\mathrm{pH}$ on the removal of heavy metals from an electroplating wastewater using $\mathrm{ZnO}$ nanoparticles as an adsorbent and found that at a $\mathrm{pH}$ below 7 (acidic), the solution was highly protonated $\left(\mathrm{H}^{+}\right)$resulting in a high positive surface charge on the surface of the adsorbent which repels the positively charged metal ions and subsequently low removal efficiency. However, due to dominant hydroxide ions $\left(\mathrm{OH}^{-}\right)$ at a pH greater than 7 , the adsorbent surface becomes negatively charged resulting to a high negative charge density that attracts more metal ions (see Fig. 8) They also reported that at a $\mathrm{pH}$ above 6 , there is possibility that the metals could precipitate to form hydroxides as a result, the adsorption process is hindered. Furthermore this trend 


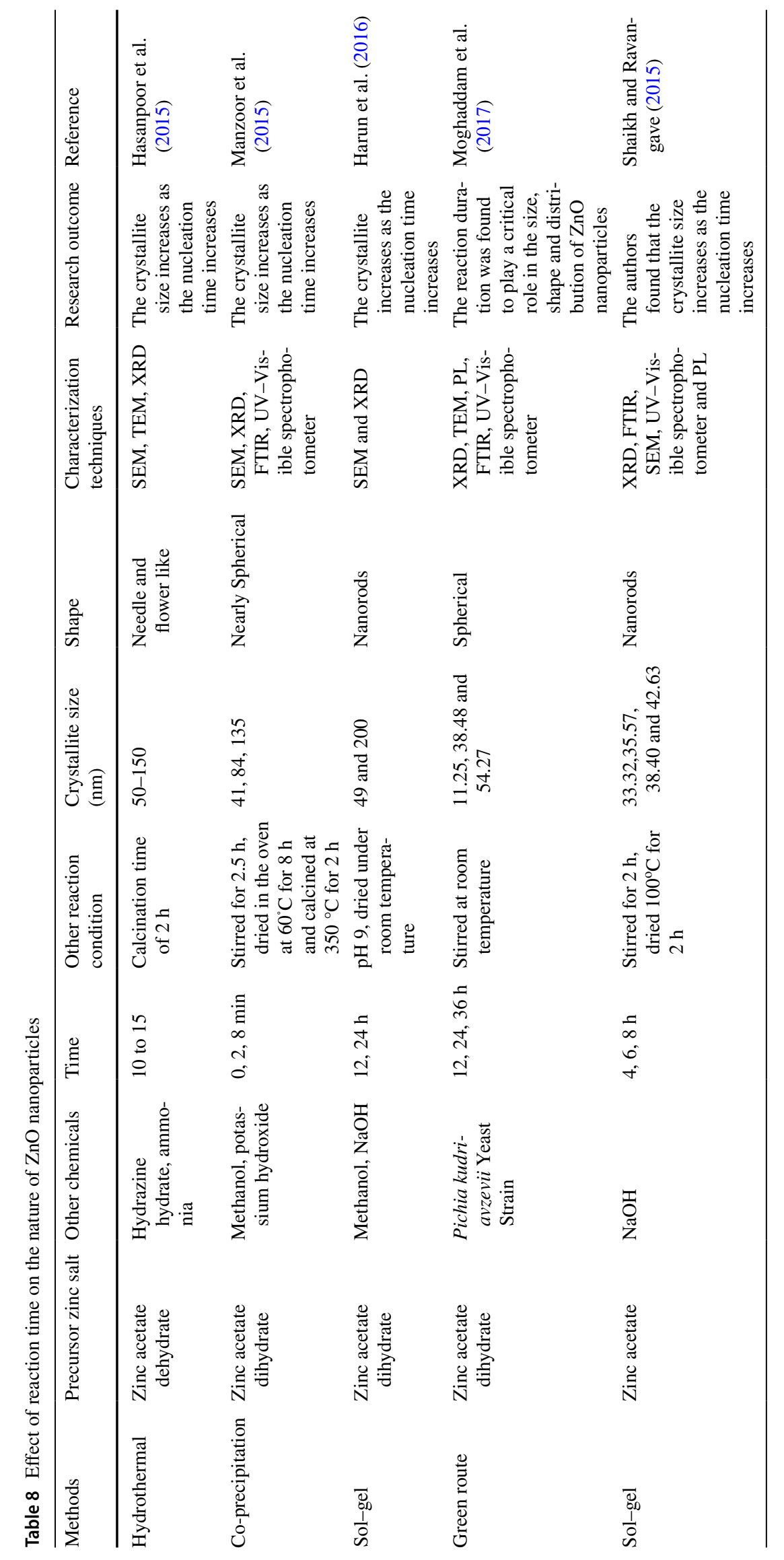


Applied Water Science (2021) 11:48

Page 29 of $41 \quad 48$

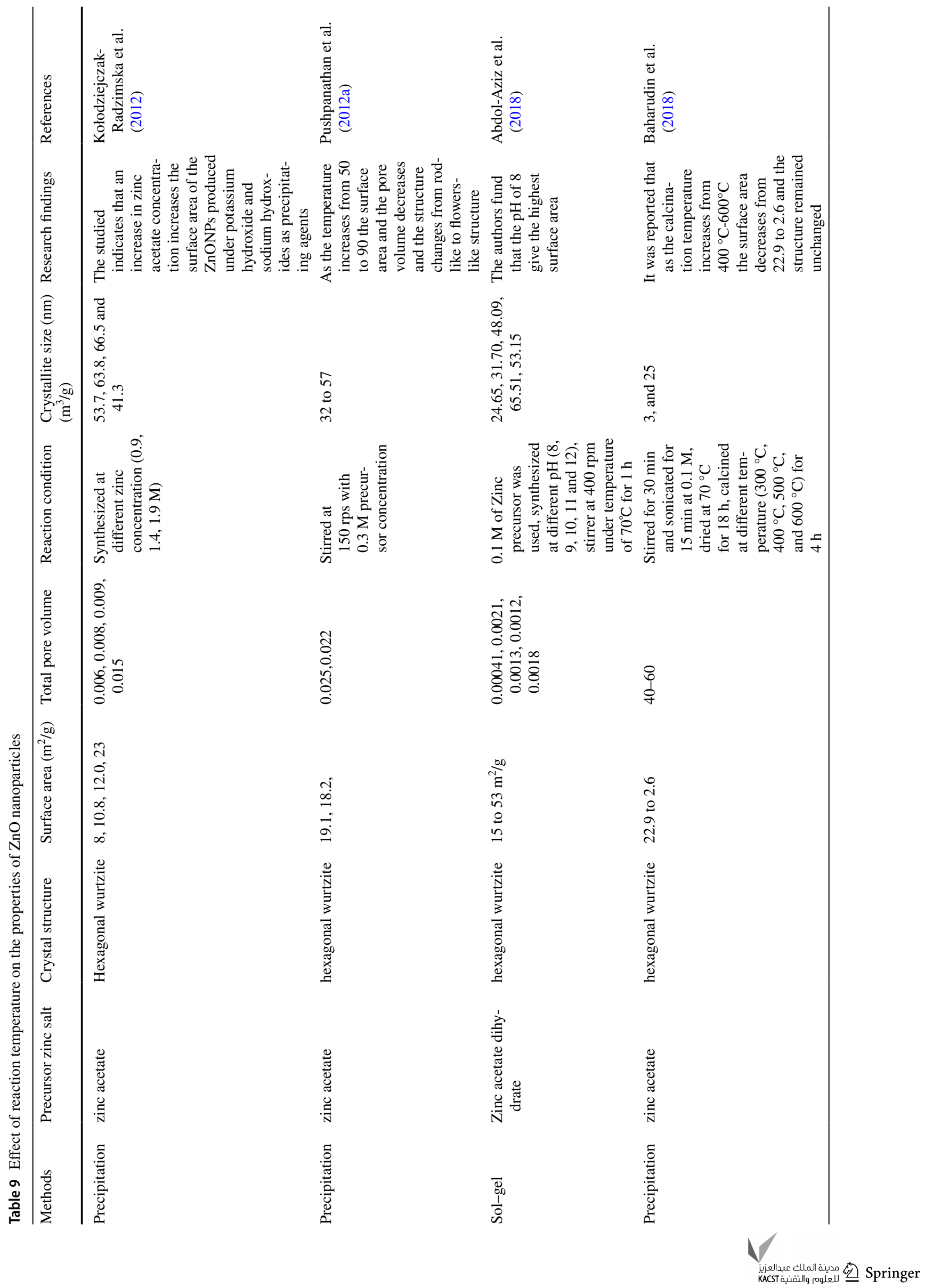




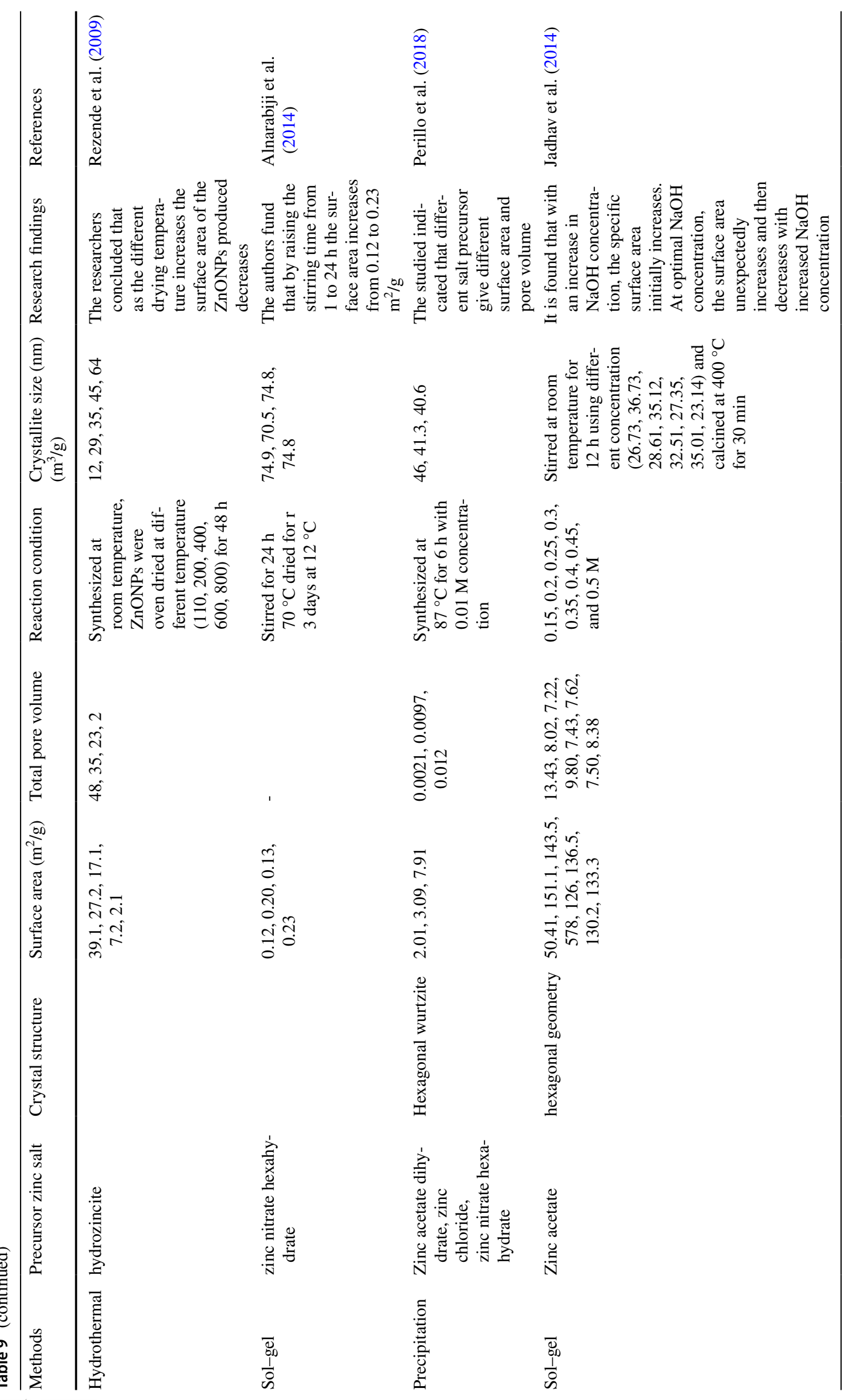


Table 10 The MCL standards for the most hazardous heavy metals. Source: Babel and Kurniawan (2003)

\begin{tabular}{lll}
\hline Heavy metal & Toxicities & MCL (mg/l) \\
\hline Arsenic & Skin manifestations, visceral cancers, vascular disease & 0.05 \\
Cadmium & Kidney damage, renal disorder, human carcinogen & 0.01 \\
Chromium & Headache, diarrhea, nausea, vomiting, carcinogenic & 0.05 \\
Copper & Liver damage, Wilson disease, insomnia & 0.25 \\
Nickel & Dermatitis, nausea, chronic asthma, coughing, human carcinogen & 0.2 \\
Lead & Damage the fetal brain, diseases of the kidneys, circulatory system, and nervous system & 0.006 \\
Mercury & Rheumatoid arthritis, and diseases of the kidneys, circulatory system, and nervous system & 0.00003 \\
\hline
\end{tabular}

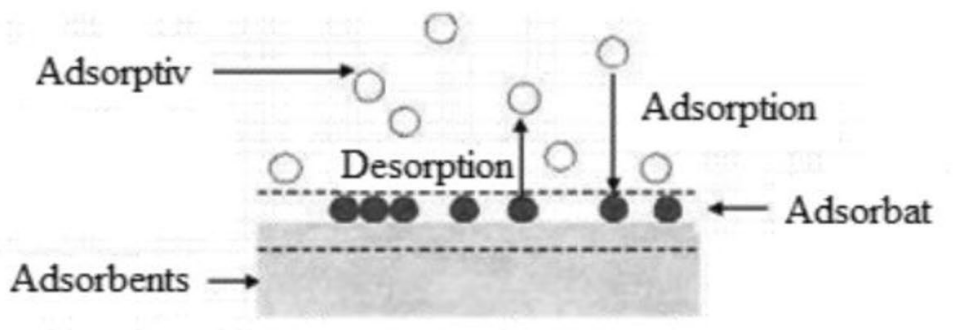

Monolayer adsorption

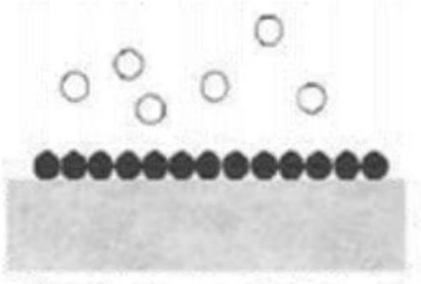

Typical for chemisorption case
Multilayer adsorption

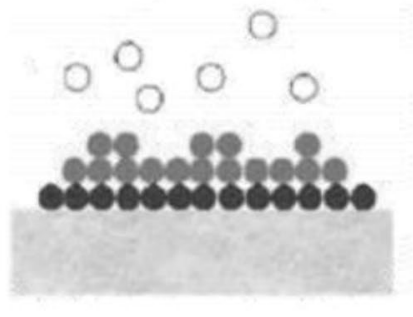

Often observed during physisorption

Fig. 6 Adsorption process and adsorption types created based on research by Christmann (2010)

Fig. 7 Adsorption mechanisms created based on research by Mathew et al. (2016)

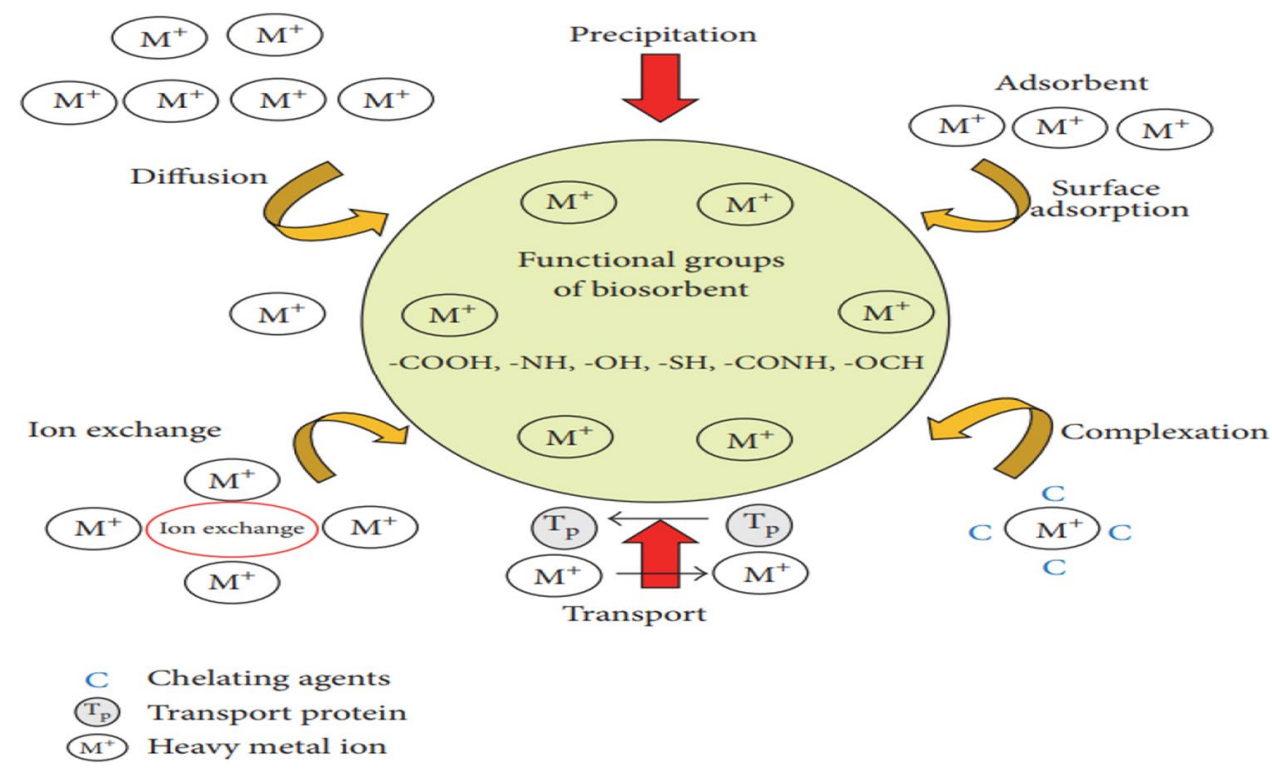




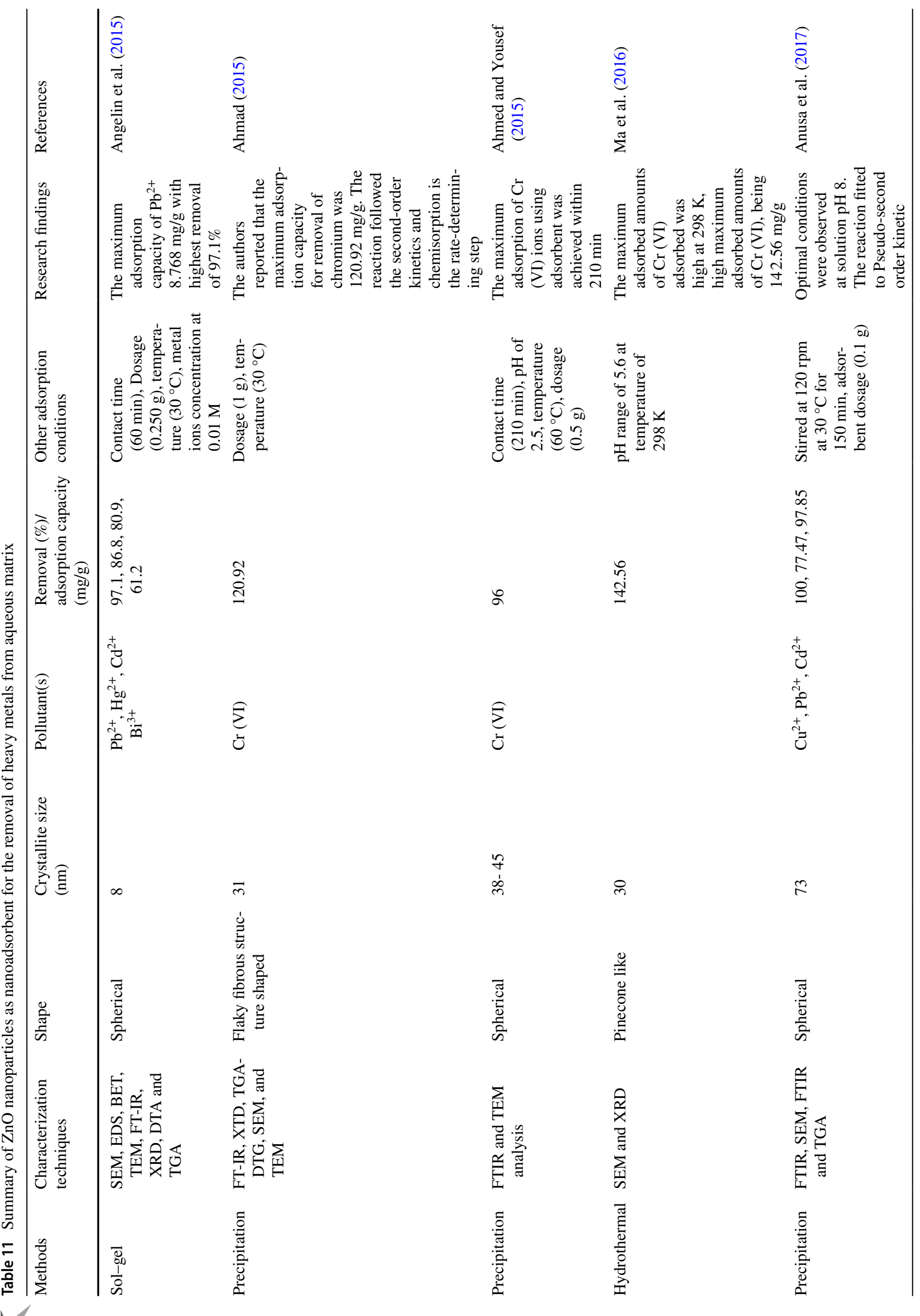




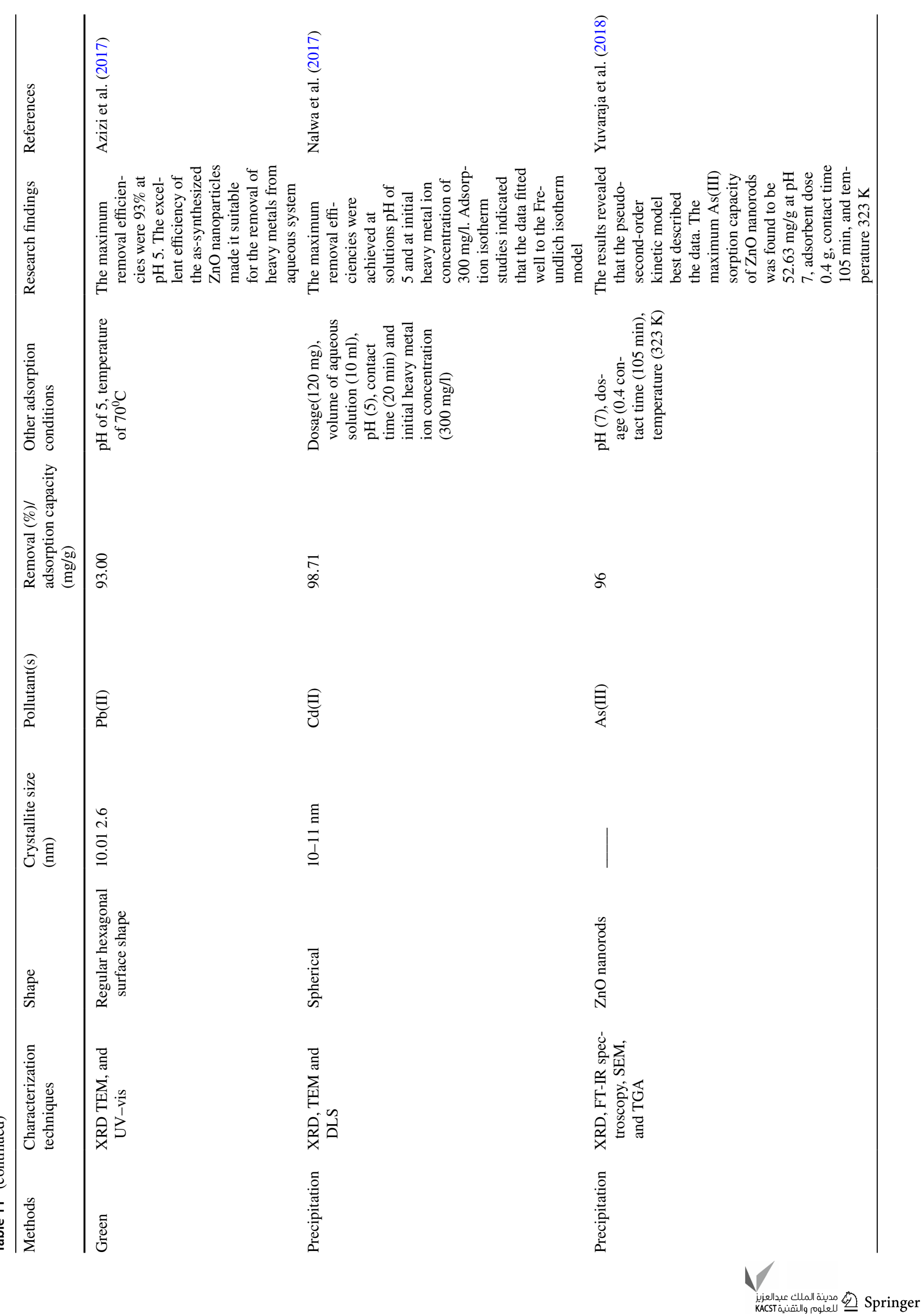




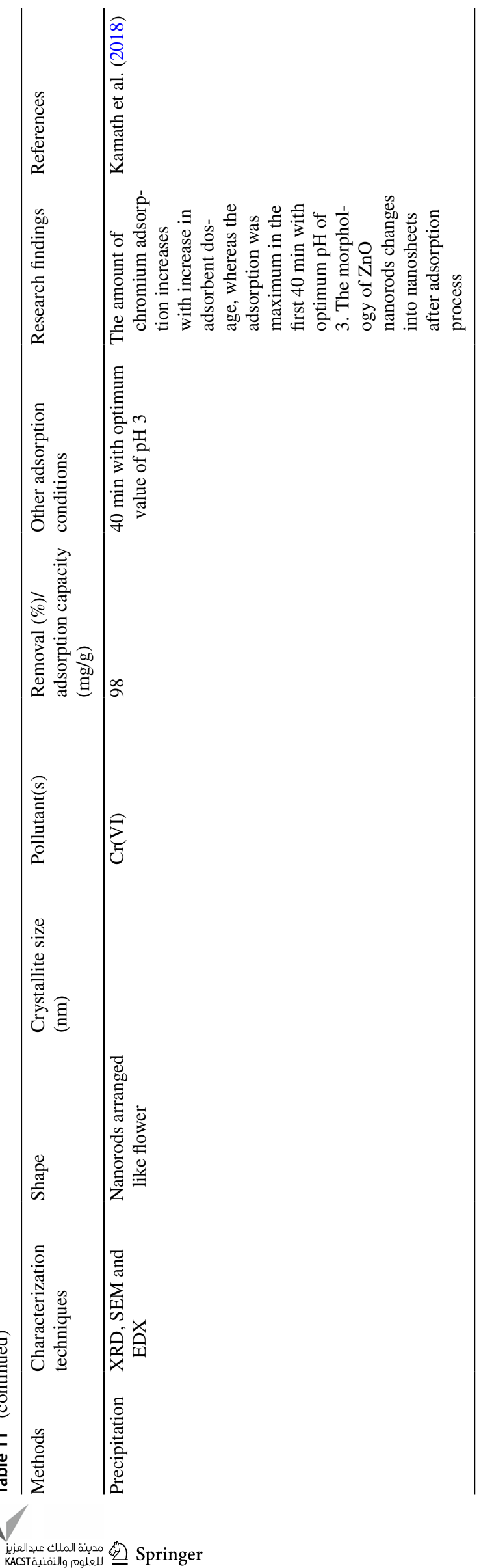

showed that electrostatic interaction played a major role in the removal of heavy metals.

\section{Conclusion}

In summary, the effects of different synthesis parameters on the textural, optical and microstructural properties of $\mathrm{ZnO}$ nanoparticles have been provided. The adsorptive behaviour of $\mathrm{ZnO}$ nanoparticles for the removal of heavy metals especially at different solution $\mathrm{pH}$ has also been summarized. Based on the review, the following conclusions were drawn. Acidic medium favoured the formation of smaller size of $\mathrm{ZnO}$ nanoparticles compared to alkaline medium. Several reports indicated a decrease in the crystallite size of $\mathrm{ZnO}$ nanoparticles as the $\mathrm{pH}$ increases from 7 to 12 . Reaction time, reaction temperature and calcination temperatures influenced the crystallite size of $\mathrm{ZnO}$ nanoparticles. Different zinc salts have little effect on the crystallite size but exerted greater influence on the morphology of the $\mathrm{ZnO}$ nanoparticle produced. The concentration of the zinc precursor shows increases in the crystallite size at a higher concentration of zinc in the solution. These findings indicated that these factors strongly affect the crystallite size and the morphology of the zinc oxide nanoparticles. The crystallite sizes with respect to each parameter also depend on the methods of synthesis of $\mathrm{ZnO}$ nanoparticles. There are still divergent views as reported by the researchers on the increase and decrease in the particle size of the $\mathrm{ZnO}$ nanoparticle. The mechanisms of the increase or decreases in the crystallite size with respect to the variations of solution $\mathrm{pH}$, synthesis temperature, different salt precursor, and synthesis time are not clearly understood and still require further investigation. Optimization of all these parameters should be carried out to fully understand the mechanism of the synthesis of $\mathrm{ZnO}$ nanoparticles. Regeneration of the $\mathrm{ZnO}$ should be performed to evaluate the cost effectiveness of $\mathrm{ZnO}$ as an adsorbent. Future research should focus on the immobilization of $\mathrm{ZnO}$ nanoparticles on suitable supports for easy separation after usage. 


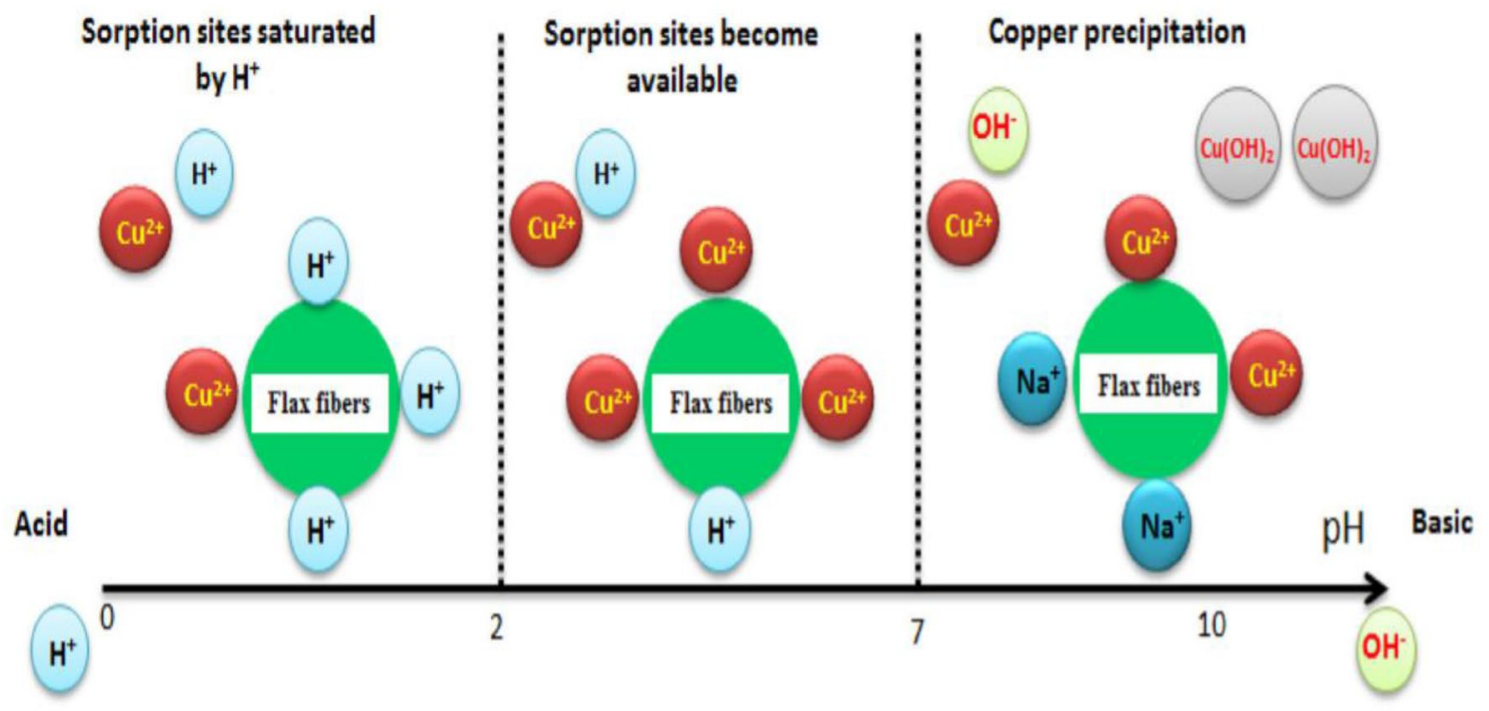

Fig. 8 Effect of pH on the adsorption of heavy metals created based on research by Abbar et al. (2017)

\section{Abbreviations}

$\begin{array}{ll}\text { AFM } & \text { Atomic force microscopy } \\ \text { BET } & \text { Brunauer, Emmett and Teller } \\ \text { DRS } & \text { Diffuse reflection spectroscopy } \\ \text { EDS } & \text { Dispersive X-ray analysis } \\ \text { FDA } & \text { Food and Drug Administration } \\ \text { FESEM } & \text { Field emission scanning electron microscopy } \\ \text { FT-IR } & \text { Fourier-transform infrared spectroscopy } \\ \text { HRTEM } & \text { High-resolution tunneling microscope } \\ \text { MCL } & \text { Maximum contaminated level } \\ \text { PL } & \text { Photoluminescence } \\ \text { PVA } & \text { Polyvinyl alcohol } \\ \text { PVP } & \text { Polyvinyl pyrrolidone } \\ \text { RS } & \text { Raman spectroscopy } \\ \text { SEM } & \text { Scanning electron microscopy } \\ \text { TEM } & \text { Transmission electron microscope } \\ \text { UV-vis } & \text { Ultraviolet-visible spectroscopy } \\ \text { XRD } & \text { X-ray powder diffraction } \\ \text { DLS } & \text { Dynamic light scattering } \\ \text { AFM } & \text { Atomic force microscopy analysis } \\ & \end{array}$

Funding The author(s) received no specific funding for this work.

\section{Compliance with ethical standards}

Conflict of interest The authors declare that they have no conflict of interest.

Ethical standards The study did not include human or animal subjects; therefore ethical approval is not required.
Open Access This article is licensed under a Creative Commons Attribution 4.0 International License, which permits use, sharing, adaptation, distribution and reproduction in any medium or format, as long as you give appropriate credit to the original author(s) and the source, provide a link to the Creative Commons licence, and indicate if changes were made. The images or other third party material in this article are included in the article's Creative Commons licence, unless indicated otherwise in a credit line to the material. If material is not included in the article's Creative Commons licence and your intended use is not permitted by statutory regulation or exceeds the permitted use, you will need to obtain permission directly from the copyright holder. To view a copy of this licence, visit http://creativecommons.org/licenses/by/4.0/.

\section{References}

Abas SNA, Ismail MHS, Kamal ML, Izhar S (2013) Adsorption process of heavy metals by low-cost adsorbent: a review. World Appl Sci J 28:1518-1530. https://doi.org/10.5829/idosi .wasj.2013.28.11.1874

Abbar B, Alema A, Marcotte S, Pantet A, Ahfir N, Bizet L, Duriatti D (2017) Experimental investigation on removal of heavy metals $\left(\mathrm{Cu}^{2+}, \mathrm{Pb}^{2+}\right.$, and $\left.\mathrm{Zn}^{2+}\right)$ from aqueous solution by flax fibres. Process Saf Environ Prot 109:639-647

Abbas A, Al-Amer AM, Laoui T, Al-Marri MJ, Nasser MS, Khraisheh M, Atieh MA (2016) Heavy metal removal from aqueous solution by advanced carbon nanotubes: critical review of adsorption applications. Sep Purif Technol 157:141-161. https://doi. org/10.1016/j.seppur.2015.11.039

Abdol-Aziz RA, Abd-Karim SF, Rosli NA (2018) The effect of pH on zinc oxide nanoparticles characteristics synthesized from banana peel. Key Eng Mater 797(271):279

Abdullah AK, Awad S, Zaraket J, Salame C (2017) Synthesis of ZnO nanopowders by using sol gel and studying their structural and electrical properties at different temperature. Energy Procedia 119:565-570. https://doi.org/10.1016/j.egypro.2017.07.080 
Ahmad R (2015) Polyaniline/ZnO nanocomposite: a novel adsorbent for the removal of $\mathrm{Cr}(\mathrm{vi})$ from aqueous solution advances in composite materials development, pp 1-23. https://www.intechopen .com/books/advances-in-composite-materials-development/polya niline-zno-nanocomposite-a-novel-adsorbent-for-the-removal-ofcr-vi-from-aqueous-solution. Accessed 13 Dec 2019

Ahmadivand A, Karabiyik M, Pala N (2016) Plasmonic photodetectors. Photodetectors. https://doi.org/10.1016/b978-1-78242-4451.00006-3

Ahmed NMP, Yousef NS (2015) Synthesis and characterization of zinc oxide nanoparticles for the removal of $\mathrm{Cr}$ (VI) International. J Sci Eng Res 65:1235-1243

Akpor OB, Otohinoyi DA, Olaolu TD, Aderiye BI (2014) Pollutants in wastewater effluents: impacts and remediation processes. Int J Enviro Res Earth Sci 3(3):50-59

Alalwan HA, Kadhom MA, Alminshid AA (2020) Removal of heavy metals from wastewater using agricultural by products. J Water Supply Res Technol AQUA 692:99-112. https://doi.org/10.2166/ aqua.2020.133

Alami ZY, Salem M, Gaidi M, Elkhamkhami J (2015) Effect of Zn concentration on structural and optical proprieties of $\mathrm{ZnO}$ thin films deposited by spray pyrolysis. Adv Energy Int J: AEIJ 2(4):11-24. https://doi.org/10.5121/aeij.2015.2402

Al-Hada NM, Saion EM, Shaari AH, Kamarudin MA, Flaifel MH, Ahmad HS, Gene SH (2014) A facile thermal-treatment route to synthesize $\mathrm{ZnO}$ nanosheets and effect of calcination temperature. PLoS ONE 9(8):103-134. https://doi.org/10.1371/ journal.pone. 0103134

Aljawfi RN, Alam MJ, Rahman F, Ahmad S, Shahee A, Kumar S (2020) Impact of annealing on the structural and optical properties of ZnONPs and tracing the formation of clusters via DFT calculation Arabian. J Chem 13:2207-2218. https://doi. org/10.1016/j.arabjc.2018.04.006

Alnarabiji MS, Yahya N, Abd-Hamid SB, Azizi K, Kashif M, Qureshi S, Alqasem B (2014) The role of surface area of $\mathrm{ZnO}$ nanoparticles as an agent for some chemical reactions. Defect Diffus Forum 354:201-213. https://doi.org/10.4028/www.scien tific.net/DDF.354.201

Alrumman SA, El-kott AF, Keshk SMAS (2016) Water pollution: source and treatment. Am J Environ Eng 6(3):88-98. https:// doi.org/10.5923/j.ajee.20160603.02

Al-Sarraf RAH, Khodair ZT, Manssor MI, Abbas RAA, Shaban AH (2018) Preparation and characterization of $\mathrm{ZnO}$ nanotripods and nanoflowers by atmospheric pressure chemical vapor deposition (APCVD) technique. AIP Conf Proc 1968:030005. https ://doi.org/10.1063/1.5039192

Alwan RM, Kadhim QA, Sahan KM, Ali AR, Mahdi RJ, Kassim NA, Jassim AN (2015) Synthesis of zinc oxide nanoparticles via sol-gel route and their characterization. Nanosci Nanotechnol 5(1):1-6. https://doi.org/10.5923/j.nn.20150501.01

Ambika S, Sundararajan M (2015) Green biosynthesis of ZnONPs using Vitex negundo L. extract: spectroscopic investigation of interaction between ZnONPs and human serum albumin. J Photochem Photobiol B 149:143-148. https://doi.org/10.1016/j. jphotobiol.2015.05.004

Angelin KB, Siva S, Kannan RS (2015) ZINC oxide nanoparticles impregnated polymer hybrids for efficient extraction of heavy metals from polluted aqueous solution. Asian J Sci Technol 6(12):2139-2150

Anusa R, Ravichandran C, Sivakumar EKT (2017) Removal of heavy metal ions from industrial waste water by nano- $\mathrm{ZnO}$ in presence of electrogenerated Fenton's reagent. Int J ChemTech Res 10(7):501-508

Ashaf R, Riaz S, Kayani ZN, Naseem S (2015) Effect of calcination on properties of ZnONPs. Mater Today Proc Part B 2(10):5468-5472. https://doi.org/10.1016/j.matpr.2015.11.071
Azhar NEZ, Shariffudin SS, Salman MR, Alrokayan AH, Haseeb AK (2017) Investigation of $\mathrm{ZnO}$ nanotetrapods at different evaporation temperatures by thermal-CVD method for OLED applications. J Mech Eng 1(19):1-19

Aziz WJ, Jassim HA (2018) A novel study of $\mathrm{pH}$ influence on $\mathrm{Ag}$ nanoparticles size with antibacterial and antifungal activity using green synthesis. World Sci News 97:139-152

Azizi S, Shahi MM, Mohamad R (2017) Green synthesis of zinc oxide nanoparticles for enhanced adsorption of lead ions from aqueous solutions: equilibrium, kinetic and thermodynamic studies. Molecules 22(6):831. https://doi.org/10.3390/molec ules22060831

Babel S, Kurniawan TA (2003) Low-cost adsorbents for heavy metals uptake from contaminated water: a review. J Hazard Mater 97(1):19-243. https://doi.org/10.1016/S0304-3894(02)00263-7

Baharudin KB, Abdullah N, Derawi D (2018) Effect of calcination temperature on the physicochemical properties of zinc oxide nanoparticles synthesized by coprecipitation. Mater Res Express. https://doi.org/10.1088/2053-1591/aae243

Bakshi MS (2015) How surfactants control crystal growth of nanomaterials. Cryst Growth Des 16(2):1104-1133

Bala N, Saha S, Chakraborty M, Maiti M, Das S, Basu R, Nandy P (2015) Green synthesis of zinc oxide nanoparticles using Hibiscus subdariffa leaf extract: effect of temperature on synthesis, anti-bacterial activity and anti-diabetic activity. RSC Adv 5(4993):4993-5003. https://doi.org/10.1039/c4ra12784f

Barhoum A, Rahier H, Benelmekki M, Assche GV (2018) Recent trends in nanostructured particles: synthesis, functionalization, and applications. Fundam Nanopart. https://doi.org/10.1016/ b978-0-323-51255-8.00024-0

Basri HH, Talib RA, Sukor R, Othman SH, Ariffin H (2020) Effect of synthesis temperature on the size of $\mathrm{ZnONPs}$ derived from pineapple peel extract and antibacterial activity of $\mathrm{ZnO}-$ starch nanocomposite films. Nanomaterials 10:1061. https://doi.org/10.3390/ nano10061061

Belay A, Bekele B, Chandra RAR (2018) Effects of temperature and polyvinyl alcohol concentrations in the synthesis of zinc oxide nanoparticles. J Nanotechnol Mater Sci 5(1):44-50. https://doi. org/10.15436/2377-1372.18.1946

Belver G, Bedia J, Gómez-Avilés A, Peñas-Garzón M, Rodriguez JJ (2019) Semiconductor photocatalysis for water purification. Nanoscale Mater Water Purif. https://doi.org/10.1016/B978-012-813926-4.00030-6

Bettini S, Pagano R, Valli L, Giancane G (2016) Enhancement of open circuit voltage of a $\mathrm{ZnO}$-based dye-sensitized solar cell by means of piezotronic effect. Chem Asian J 11(8):1240-1245. https://doi. org/10.1002/asia.201501325

Buazar F, Bavi M, Kroushawi F, Halvani M, Khaledi-Nasab A, Hossieni SA (2016) Potato extract as reducing agent and stabiliser in a facile green one-step synthesis of ZnONPs. J Exp Nanosci 11(3):175-184. https://doi.org/10.1080/17458 080.2015.1039610

Bushra R, Ahmeda A, Shahadat M (2017) Mechanism of adsorption on nanomaterials, pp 90-111. https://www.researchgate.net/publi cation/310771898_Mechanism_of_Adsorption_on_Nano_mater ials

Cai Y, Liu L, Tian H, Yang Z, Luo Z (2019) Adsorption and desorption performance and mechanism of tetracycline hydrochloride by activated carbon-based adsorbents derived from sugar cane bagasse activated with $\mathrm{ZnCl} 2$. Molecules 24:4534. https://doi. org/10.3390/molecules24244534

Campisi S, Schiavoni M, Chan-Thaw CE, Villa A (2016) Untangling the role of the capping agent in nanocatalysis: recent advances and perspectives. Catalysts 6:185. https://doi.org/10.3390/catal 6120185 
Cao H (2017) Synthesis, characterization, and applications of zerodimensional (0D) nanostructures. https://doi.org/10.1002/97835 27698158.ch2. Accessed 20 May 2019

Cao D, Gong S, Shu X, Zhu D, Liang S (2019) Preparation of ZnONPs with high dispersibility based on oriented attachment process. Nanoscale Res Lett 14:210. https://doi.org/10.1186/s1167 1-019-3038-3

Chakraborty A, Saha BB, Ng KC, Koyama S, Srinivasan K (2009) Heoretical insight of physical adsorption for a single-component adsorbent + adsorbate system: I. Thermodynamic property surfaces. Langmuir 25(4):2204-2211. https://doi.org/10.1021/la803 $289 \mathrm{p}$

Chandramohan K, Valli R, Mageswari B (2017) Synthesis and characterization of zinc nanopartical from luffa acutangula. Int J Sci Res 6(11):339-340

Chitra K, Annadurai G (2014) antibacterial activity of ph-dependent biosynthesized silver nanoparticles against clinical pathogen. Biomed Res Int. https://doi.org/10.1155/2014/725165

Chitha MJ, Sathya M, Pushpanathan K (2015) Effect of pH on crystal size and photoluminescence property of ZnONPs prepared by chemical precipitation method. Acta Metall Sin (Engl Lett) 28(3):394-404. https://doi.org/10.1007/s40195-015-0218-8

Christmann K (2010) Adsorption. Lecture series 2010/2011: "Modern Methods in Heterogeneous Catalysis Research Institut für Chemie und Biochemie, Freie Universität, Berlin. http://www. fhierlin.mpg.de/acnew/department/pages/teaching/pages/teach ing_wintersemester_2010_2011/klaus_christmann_adsorption 101105.pdf. Accessed 23 June 2018

Dalod ARM, Grendal OG, Skjærvø SL, Inzani K, Selbach SM, Henriksen L, Beek WV, Grande T, Einarsrud M (2017) Controlling oriented attachment and in situ functionalization of $\mathrm{TiO} 2$ nanoparticles during hydrothermal synthesis with APTES. J Phys Chem 121(21):11897-11906. https://doi.org/10.1021/acs.jpcc.7b02604

Dange SS, Dange SN, More PS (2015) Effect of pH on morphology of $\mathrm{Cu}$ added $\mathrm{ZnO}$ nanostructures by precipitation method. Int J Innov Res Sci Eng Technol 4(9):8637-8642. https://doi. org/10.15680/IJIRSET.2015.0409131

Degen A, Kosec M (2000) Effect of pH and impurities on the surface charge of zinc oxide in aqueous solution. J Eur Ceram Soc 20:667-673. https://doi.org/10.1016/S0955-2219(99)00203-4

Duan P, Yan C, Zhou W, Ren D (2016) Development of fly ash and iron ore tailing based porous geopolymer for removal of $\mathrm{Cu}(\mathrm{II})$ from wastewater. Ceram Int 42:13507-13518

Eadi SB, Kim S, Jeong SO (2017) Effect of surfactant on growth of $\mathrm{ZnO}$ nanodumbbells and their characterization. J Chem. https:// doi.org/10.1155/2017/1728345

Engwa GA, Ferdinand PU, Nwalo FN, Unachukwu MN (2016) Mechanism and health effects of heavy metal toxicity in humans, pp 1-23. https://www.intechopen.com/books/poisoning-in-themodern-world-new-tricks-for-an-old-dog-/mechanism-and-healt h-effects-of-heavy-metal-toxicity-in-humans

Erhard N, Holleitner A (2015) 13-Semiconductor nanowires studied by photocurrent spectroscopy semiconductor nanowires materials, synthesis, characterization and applications. Series in electronic and optical materials, pp 365-391. https://www.elsevier. com/books/semiconductor-nanowires/arbiol/978-1-78242-253-2

Etcheverry LP, Flores WH, Silva DL, Moreira EC (2017) Annealing effects on the structural and optical properties of $\mathrm{ZnO}$ nanostructures. Mater Res 21(2):1-7. https://doi. org/10.1590/1980-5373-mr-2017-0936

Ezhilarasi AA, Vijaya JJ, Kennedy JL, Vasanth M (2016) Green synthesis of $\mathrm{Mg}$ doped zinc oxide nanoparticles using aloe vera plant extract and its characterization. J Chem Pharma Sci 9(3):1450-1453
Fakhari S, Jamzad M, Fard HF (2019) Green synthesis of zinc oxide nanoparticles: a comparison. Green Chem Lett Rev 12(1):19-24. https://doi.org/10.1080/17518253.2018.1547925

Geetha A, Sakthivel R, Mallika J, Kannusamy R, Rajendran R (2016) Green synthesis of antibacterial zinc oxide nanoparticles using biopolymer Azadirachta indica gum. Orient J Chem 32(2):955-963. https://doi.org/10.13005/ojc/320222

Getie S, Belay A, Chandra Reddy AR, Belay Z (2017) Synthesis and characterizations of zinc oxide nanoparticles for antibacterial applications. J Nanomed Nanotechnol. https://doi. org/10.4172/2157-7439.S8-004

Ghannam H, Chahboun A, Turmine M (2019) Wettability of zinc oxide nanorod surfaces. R Soc Chem Adv 9:38289-38297. https://doi.org/10.4172/2157-7439.S8-004

Ghassan AA, Mijan N, Taufiq-Yap YH (2019) Nanomaterials: an overview of nanorods synthesis and optimization. https://doi. org/10.5772/intechopen.84550. Accessed 20 May 2020

Girish CR, Murty VR (2017) Mass transfer studies on adsorption of phenol from wastewater using lantana camara, forest waste. Int J Chem Eng. https://doi.org/10.1155/2016/5809505

Gopal VRV, Kamila S (2017) Effect of temperature on the morphology of ZnONPs: a comparative study. Appl Nanosci 7:75-82. https://doi.org/10.1007/s13204-017-0553-3

Goryacheva IY (2016) Chapter 4-labels for optical immunotests. In: Comprehensive analytical chemistry, vol 72, pp 79-131. https://www.sciencedirect.com/handbook/compr ehensive-analytical-chemistry/vol/72/suppl/C. Accessed 20 May 2019

Gulati S, Sachdeva M, Bhasin KK (2016) Capping agents in nanoparticle synthesis: Surfactant and solvent system. In: AIP conference proceedings. https://doi.org/10.1063/1.5032549. Accessed June 2020

Gunatilake SK (2015) Methods of removing heavy metals from industrial wastewater. J Multidiscip Eng Sci Stud: JMESS 1(1):12-18

Gupta VK, Suhas A, Nayak S, Chaudhary AM, Tyagi I (2014) Removal of Ni (II) ions from water using scrap tire. J Mol Liquids 190:215-222. https://doi.org/10.1016/j.molliq.2013.11.008

Gusatti M, Barroso GS, Campos CEM, Souza DAR, Rosário JA, Lima RB, Silva LA, Riella HG, Kuhnen NC (2011) Effect of different precursors in the chemical synthesis of $\mathrm{ZnO}$ nanocrystals. Effect of different precursors in the chemical synthesis of $\mathrm{ZnO}$ nanocrystals. Mater Res. https://doi.org/10.1590/S1516-14392 011005000035

Hajiashafi S, Motakef-Kazemi N (2018) Green synthesis of zinc oxide nanoparticles using parsley extract. Nanomed Res J 3(1):44-50. https://doi.org/10.22034/nmrj.2018.01.007

Harun K, Mansor N, Ahmad ZA, Mohamad AZ (2016) Electronic properties of ZnONPs synthesized by sol-gel method: a LDA+ U calculation and experimental study. Procedia Chem 19:125-132. https://doi.org/10.1016/j.proche.2016.03.125

Hasan M, Ullah I, Zulfiqar H, Naeem K, Iqbal A, Gul H, Ashfaq M, Mahmood N (2018) Biological entities as chemical reactors for synthesis of nanomaterials: progress, challenges and future perspective. Mater Today Chem 8:13-28. https://doi.org/10.1016/j. mtchem.2018.02.003

Hasanpoor M, Aliofkhazraei M, Delavari H (2015) Microwaveassisted synthesis of zinc oxide nanoparticles. Procedia Mater Sci 11:320-325. https://doi.org/10.1016/j.mspro.2015.11.101

Hedayati K (2016) Fabrication and optical characterization of zinc oxide nanoparticles prepared via a simple sol-gel method. J Nanostruct 5:395-401. https://doi.org/10.7508/JNS.2015.04.010

Herrera-Rivera R, Olvera R, Maldonado A (2017) Synthesis of $\mathrm{ZnO}$ nanopowders by the homogeneous precipitation method: use of taguchi's method for analyzing the effect of different variables. J Nanomater 1:1. https://doi. org/10.1155/2017/4595384

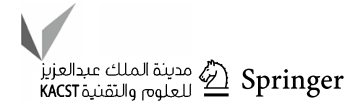


Hu H, Huang X, Deng C, Chen X, Qian Y (2007) Hydrothermal synthesis of $\mathrm{ZnO}$ nanowires and nanobelts on a large scale. Mater Chem Phys 106:58-62. https://doi.org/10.1016/j.matchemphy s.2007.05.016

Iftekhar S, Ramasamy DL, Srivastava V, Asif MB, Sillanpa M (2018) Understanding the factors affecting the adsorption of Lanthanum using different adsorbents: a critical review. Chemosphere 204:413-430. https://doi.org/10.1016/j.chemospher e.2018.04.053

Ihsanullah AFA, Al-Khaldi FA, Abusharkh B, Khaled M, Atieh MA et al (2015) Adsorptive removal of cadmium (II) ions from liquid phase using acid modified carbon-based adsorbents. J Mol Liquids 204:255-263. https://doi.org/10.1016/j.molliq.2015.01.033

Ikono R, Akwalia PR, Bambang W, Sukarto A, Rochman NT (2012) Effect of PH variation on particle size and purity of nano zinc oxide synthesized by sol-gel method. Int J Eng Technol: IJET IJENS 2(6): 1-9

Indramahalakshmi G (2017) Characterization and antibacterial activity of zinc oxide nanoparticles synthesized using Opuntia ficus indica fruit aqueous extract. Asian J Phys Chem Sci 3(2):1-7. https://doi.org/10.9734/AJOPACS/2017/35917

Jadhav NA, Singh PK, Rhee HW, Bhattacharya B (2014) Effect of variation of average pore size and specific surface area of $\mathrm{ZnO}$ electrode (WE) on efficiency of dye-sensitized solar cells. Nanoscale Res Lett 9:575

Jamal A, Awad R, Yusef H (2019) Evaluation of antimicrobial activity of ZnONPs against foodborne pathogens. Int J Curr Microbiol Appl Sci 8(11):2000-2025. https://doi.org/10.20546/ijcmas

Jin XYuC, Li Y, Qi Y, Yang L, Zhao G, Hu H (2011) Preparation of novel nano-adsorbent based on organic-inorganic hybrid and their adsorption for heavy metals and organic pollutants presented in water environment. J Hazard Mater 186:1672-1680

Jin X, Götz M, Wille S, Mishra YK, Adelung R, Zollfrank C (2013) A novel concept for self-reporting materials: stress sensitive photoluminescence in $\mathrm{ZnO}$ tetrapod filled elastomers. Adv Mater 25(9):1342. https://doi.org/10.1002/adma.201203849

Kahaman O, Binzet R, Turunc E, Dogen A, Arslan H (2018) Synthesis, characterization, antimicrobial and electrochemical activities of zinc oxide nanoparticles obtained from Sarcopoterium spinosum (L) spach leaf extract. Mater Res Express 5(11):1-10. https://doi. org/10.1088/2053-1591/aad953

Kamath S, Gopal V, Ramanjaneyalu V, Kamila S (2018) Application of $\mathrm{ZnO}$ nano rods for the batch adsorption of $\mathrm{Cr}(\mathrm{VI})$ : a study of kinetics and isotherms. Am J Appl Sci 16(3):1-12. https://doi. org/10.3844/ajassp.2019.101.112

Kayani ZN, Saleemi F, Batool I (2015) Effect of calcination temperature on the properties of ZnONPs. Appl Phys A. https://doi. org/10.1007/s00339-015-9019-1

Khan M, Hameedullah M, Ansari A, Ahmad E, Khan RL, Alam M, Khan W, Husain FM, Ahmad I (2014) Flower-shaped ZnONPs synthesized by a novel approach at near-room temperatures with antibacterial and antifungal properties. Int J Nanomed 9(1):853864. https://doi.org/10.2147/IJN.S47351

Koao LF, Dejene FB, Swart HC (2015) Effect of pH on the properties of $\mathrm{ZnO}$ nanostructures prepared by chemical bath deposition method. In: Proceedings of SAIP2015. https://www.resea rchgate.net/publication/306000264_Effect_of_pH_on_the_prope rties_of_ZnO_nanostructures_prepared_by_chemical_bath_ deposition_method. Accessed 12 Feb 2020

Kołodziejczak-Radzimska A, Markiewicz E, Jesionowski T (2012) Structural characterisation of $\mathrm{ZnO}$ particles obtained by the emulsion precipitation method. J Nanomater. https://doi. org/10.1155/2012/656353

Koutu V, Shastri L, Malik MM (2016) Effect of NaOH concentration on optical properties of zinc oxide nanoparticles. Mater Sci Pol 34(4):819-827. https://doi.org/10.1515/msp-2016-0119
Kumar SS, Venkateswarlu P, Rao VR, Rao GN (2013) Synthesis, characterization and optical properties of zinc oxide nanoparticles. Int Nano Lett 3:1-6. https://doi.org/10.1186/2228-5326-3-30

Kumari M, Misha A, Pandey S, Singh SP, Chaudhy V, Mudiam MKR, Shukla S, Kakkar P, Nautiyal CS (2016) Physico-chemical condition optimization during biosynthesis led to development of improved and catalytically efficient gold nano particles. Sci Rep 6:27575

Kvitek L, Prucek K, Panacek A, Soukupova J (2016) Physicochemical aspects of metal nanoparticle preparation, pp 1-34. https ://doi.org/10.5772/intechopen.89954. Accessed 12 April 2020

Kyoung-Ku K, Byungjin L, Chang-Soo L (2019) Recent progress in the synthesis of inorganic particulate materials using microfluidics. J Taiwan Inst Chem Engi 98:2-19. https://doi. org/10.1016/j.jtice.2018.08.027

Kyzas GZ, Kostoglou M (2014) Green adsorbents for wastewaters: a critical review. Materials (Basel) 7(1):333-364. https://doi. org/10.3390/ma7010333

Ladu JLC, Athiba AL, Lako STV, Alfred ML (2018) Investigation on the impact of water pollution on human health in Juba County, Republic of South Sudan. J Environ Pollut Hum Health 6(3):89-95. https://doi.org/10.12691/jephh-6-3-2

Lata S, Singh PK, Samadder SR (2019) Regeneration of adsorbents and recovery of heavy metals: a review. Int J Environ Sci Technol 12:1461-1478. https://doi.org/10.1007/s13762-014-0714-9

Layek A, Misha G, Sharma A, Spasova M, Dhar M, Chowdhury A, Bandyopadhyaya R (2012) A generalized three-stage mechanism of $\mathrm{ZnO}$ nanoparticle formation in homogeneous liquid medium. J Phys Chem 116:24757-24769. https://doi. org/10.1021/jp211613b

Leonardi SG (2017) Two-dimensional zinc oxide nanostructures for gas sensor applications. Chemosensors 5(17):1-28. https://doi. org/10.3390/chemosensors5020017

Liu H, Zhang H, Wang J, Wei J (2020) Effect of temperature on the size of biosynthesized silver nanoparticle: deep insight into microscopic kinetics analysis. Arab J Chem 13(1):1011-1019

Ma J, Zuo-Jiang S, He Y, Sun Q, Wang Y, Liu W, Sun S, Chen K (2016) A facile, versatile approach to hydroxyl-anchored metal oxides with high $\mathrm{Cr}(\mathrm{VI})$ adsorption performance in water treatment. R Soc Open Sci 3(11):160524. https://doi.org/10.1098/ rsos. 160524

Maduabuchi MN (2018) Agricultural waste materials as a potential adsorbent for removal of heavy metals in wastewater. J Waste Manag Xenobiotics 1(1):1-4. https://doi.org/10.23880/oajwx $-16000104$

Mahdavi S, Jalali M, Afkhami A (2012) Removal of heavy metals from aqueous solutions using $\mathrm{Fe}_{3} \mathrm{O}_{4}, \mathrm{ZnO}$, and $\mathrm{CuO}$ nanoparticles. J Nanopart Res 14:846. https://doi.org/10.1007/s1105 1-012-0846-0

Mahmoodian H, Moradi O, Shariatzadeha B, Saleh TA, Tyagi I, Maity A, Asif M, Gupta KV (2015) Enhanced removal of methyl orange from aqueous solutions by poly HEMA-chitosan-MWCNT nano-composite. J Mol Liquids 202:189-198. https://doi.org/10.1016/j.molliq.2014.10.040

Mahmoud MA (2015) Kinetics and thermodynamics of aluminum oxidenanopowder as adsorbent for Fe (III) from aqueoussolution. Beni-Suef Univ J Basic Appl Sci 4(2015):142-149. https ://doi.org/10.1016/j.molliq.2014.10.040

Mallika NA, Reddy AR, Reddy KV (2015) Annealing effects on the structural and optical properties of ZnONPs with PVA and CA as chelating agents. J Adv Ceram 4(2):123-129. https://doi. org/10.1007/s40145-015-0142-4

Manzoor U, Zaha FT, Rafique S, Moin MT, Mujahid M (2015) Effect of synthesis temperature, nucleation time, and postsynthesis heat treatment of ZnONPs and its sensing properties. J Nanomater. https://doi.org/10.1155/2015/189058 
Marcus C, Paul N, Warburton A (2007) ZnO tetrapod nanocrystals. Mater Today 10(5):50-54. https://doi.org/10.1016/S1369 -7021(07)70079-2

Mathew BB, Jaishankar M, Biju VG, Beeregowda KN (2016) Role of bioadsorbents in reducing toxic metals. J Toxicol 1:1. https ://doi.org/10.1155/2016/4369604

Mayekar J, Dhar V, Radha S (2014) Role of salt precursor in the synthesis of zinc oxide nanoparticles. Int J Res Eng Technol 3(3):43-45. https://doi.org/10.15623/ijret.2014.0303008

Meenakshi G, Sivasamy A (2017) Synthesis and characterization of zinc oxide nanorods and its photocatalytic activities towards degradation of 2,4-D. Ecotoxicol Environ Saf 135:243-325

Moazzen MA, Borghei SM, Taleshi F (2013) Change in the morphology of ZnONPs upon changing the reactant concentration. Appl Nanosci 3:295-302. https://doi.org/10.1007/s1320 4-012-0147-z

Modi G (2015) Zinc oxide tetrapod: a morphology with multifunctional applications advances in natural sciences. Nanosci Nanotechnol 6:1-8. https://doi.org/10.1088/2043-6262/6/3/033002

Moghaddam AB, Moniri M, Azizi S, Rahim RA, Ariff AB, Saad WZ, Namvar F, Navaderi M, Mohamad R (2017) Biosynthesis of ZnONPs by a new Pichia kudriavzevii yeast strain and evaluation of their antimicrobial and antioxidant activities. Molecules 22(6):872

Mohammadi FM, Ghasemi N (2018) Influence of temperature and concentration on biosynthesis and characterization of zinc oxide nanoparticles using cherry extract. J Nanostruct Chem 8:93-102. https://doi.org/10.1007/s40097-018-0257-6

Monisha J, Tenzin T, Naresh A, Blessy BM, Krishnamurthy NB (2014) Toxicity, mechanism and health effects of some heavy metals. Interdiscip Toxicol 7(2):60-72. https://doi.org/10.2478/intox -2014-0009

Mornani EG, Mosayebian P, Dorranian D, Behzad K (2016) Effect of calcination temperature on the size and optical properties of synthesized ZnONPs. J Ovonic Res 12(2):75-80

Mrad M, Chouchene B, Chaabane TB (2018) Effects of zinc precursor, basicity and temperature on the aqueous synthesis of $\mathrm{ZnO}$ nanocrystals. S Afr J Chem 71:103-110. https://doi.org/10.17159 /0379-4350/2018/v71a13

Nalwa K, Thakur A, Sharma N (2017) Synthesis of ZnONPs and its application in adsorption. Adv Mater Proc 2(11):697-703. https ://doi.org/10.5185/amp/2017/696

Nasrollahzadeh M, Issaabadi Z, Sajjadi M, Sajadi M, Atarod M (2019) Chapter 2-types of nanostructure. Interface Sci Technol 28:29-80

Nejati K, Rezvani Z, Pakizevand R (2016) Synthesis of ZnONPs and investigation of the ionic template effect on their size and shape. Int Nano Lett 1(2):75-81

Ogbomida ET, Nakayama S, Bortey-Sam N, Oroszlany B, Tongo I, Enuneku AA, Ogbeide O, Ainerua MO, Fasipe IP, Ezemonye LI, Mizukawa H, Ikenaka Y, Ishizuka IM (2018) Accumulation patterns and risk assessment of metals and metalloid in muscle and official of free-range chickens, cattle and goat in Benin City, Nigeria. Ecotoxicol Environ Saf 151:98-108. https://doi. org/10.1016/j.ecoenv.2017.12.069

Osman DAM, Mustafa MA (2015) Synthesis and characterization of zinc oxide nanoparticles using zinc acetate dihydrate and sodium hydroxide. J Nanosci Nanoeng 1(4):248-251

Ouyang TD, Zhuo YZ, Hu L, Zeng Q, Hu Y, He Z (2019) Research on the adsorption behavior of heavy metal ions by porous material prepared with silicate. Minerals 9(291):1-16. https://doi. org/10.3390/min9050291

Özgür Ü, Alivov YI, Liu C, Teke A, Reshchikov M, Doğan S, Avrutin VC, Cho SJ, Morkoç AH (2005) A comprehensive review of $\mathrm{ZnO}$ materials and devices. J Appl Phys 98(4):041301. https:// doi.org/10.1063/1.1992666
Parihar V, Raja M, Paulose R (2018) A brief review of structural, electrical and electrochemical properties of zinc oxide nanoparticles. Rev Adv Mater Sci 53:119-130. https://doi.org/10.1515/ rams-2018-0009

Parra MR, Haque FZ (2014) Aqueous chemical route synthesis and the effect of calcination temperature on the structural and optical properties of ZnONPs. J Mater Technol 3(4):363-369. https ://doi.org/10.1016/j.jmrt.2014.07.001

Pelicano CM, Magdaluyo E, Ishizumi A (2016) Temperature dependence of structural and optical properties of ZnONPs formed by simple precipitation method. In: MATEC Web of conferences, published by EDP sciences, vol 43, pp 1-4

Peng S, Wu G, Song W, Wang Q (2013) Application of flower-like $\mathrm{ZnO}$ nanorods gas sensor detecting $\mathrm{SF}_{6}$ decomposition products. J Nanomater. https://doi.org/10.1155/2013/135147

Peng H, Sun X, Weng W, Fang X (2017) 4-electronic polymer composite polymer materials for energy and electronic applications, pp 107-149. https://doi.org/10.1016/C2015-0-01541-6. Accessed 20 May 2020

Perillo PM, Atia MN, Rodríguez DF (2018) Studies on the growth control of $\mathrm{ZnO}$ nanostructures synthesized by the chemical method. Revista Matér 23(2):1-7. https://doi.org/10.1590/ S1517-707620180002.0467

Perveena R, Shujaat S, Qureshi Z, Nawaz S, Khand MI, Iqbal M (2020) Green versus sol-gel synthesis of ZnONPs and antimicrobial activity evaluation against panel of pathogens. J Mater Res Technol 9:7817-7827. https://doi.org/10.1016/j. jmrt.2020.05.004

Phan CM, Nguyen HM (2017) Role of capping agent in wet synthesis of nanoparticles. Phys Chem A 121(17):3213-3219. https://doi. org/10.1021/acs.jpca.7b02186

Polte J, Ahner TT, Delissen F, Sokolov S, Emmerling F, Thuenemann AF, Kraehnert R (2010) Mechanism of gold nanoparticle formation in the classical citrate synthesis method derived from coupled in situ XANES and SAXS evaluation. J Am Chem Soc 132:1296-1301. https://doi.org/10.1021/ja906506j

Purwaningsih SY, Pratapa S, Darminto T (2016) Synthesis of nanosized $\mathrm{ZnO}$ particles by co-precipitation method with variation of heating time. In: AIP conference proceedings, vol 1710, no 1. https://doi.org/10.1063/1.4941506

Pushpanathan K, Sathya M, Chitha MJ, Gowthami S, Santhi R (2012a) Influence of reaction temperature on crystal structure and band gap of ZnONPs. Mater Manuf Process 27(12):1-10. https://doi. org/10.1080/10426914.2012.700163

Pushpanathan K, Sathya S, Chithra SJ, Gowthami S, Santhi R (2012b) Influence of reaction temperature on crystal structure and band gap of ZnONPs. Mater Manuf Process 27(12):1334-1342. https ://doi.org/10.1080/10426914.2012.700163

Rafaie HA, Samat NA, MdNora R (2014) Effect of pH on the growth of zinc oxide nanorods using Citrus aurantifolia extracts. Mater Lett 137:297-299. https://doi.org/10.1016/j.matlet.2014.09.033

Raliya R, Tarafdar JC (2013) Biosynthesis and characterization of zinc, magnesium and titanium nanoparticles: an eco-friendly approach. Int Nano Lett 4:1-93. https://doi.org/10.1007/s4008 9-014-0093-8

Ravangave LS, Shaikh RS (2017) Influence of $\mathrm{pH}$ on structure, morphology and UV-visible spectra of ZnO nanorod. Int J Eng Sci Invent 6(11):76-79

Ray PZ, Shipley HJ (2015) Inorganic nano-adsorbents for the removal of heavy metals and arsenic: a review. RSC Adv 5(38):2988529907. https://doi.org/10.1039/C5RA02714D

Rezende CP, Silva JB, Mohallem NDS (2009) Influence of drying on the characteristics of zinc oxide nanoparticles. Braz J Phys 39(1a):248251. https://doi.org/10.1590/s0103-97332009000200022

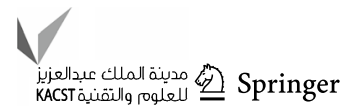


Ribut SH, Abdullah CA, Mustafa M, Yusoff MZM, Azman SNA (2018) Influence of $\mathrm{pH}$ variations on zinc oxide nanoparticles and their antibacterial activity. Mater Res Express 6(2):1-9

Ruszkiewicz JA, Pinkas A, Ferrer B, Peres TV, Tsatsakis A, Aschner $M$ (2017) Neurotoxic effect of active ingredients in sunscreen products, a contemporary review. Toxicol Rep 4:245-259. https ://doi.org/10.1016/j.toxrep.2017.05.006

Ruys A (2019) 15-Refractory and other specialist industrial applications of alumina. Biomed Clin Appl. https://doi.org/10.1016/ C2017-0-01189-8

Salahuddin NA, El-Kemary M, Ibrahim EM (2015) Synthesis and characterization of ZnONPs via precipitation method: effect of annealing temperature on particle size. Nanosci Nanotechnol 5(4):82-88. https://doi.org/10.5923/jnn2015050402

Salmani MH, Zarei S, Ehrampoush MH, Danaie S (2013) Evaluations of $\mathrm{pH}$ and high ionic strength solution effect in cadmium removal by zinc oxide nanoparticles. J Appl Sci Environ Manag 17(4):583-593. https://doi.org/10.4314/jasem.v17i4.17

Samei J, Shokuhfar A, Kandjani AE, Vaezi MR (2008) Effect of synthesis temperature on the morphology of $\mathrm{ZnO}$ nanoparticles obtained via a novel chemical route. Defect Diffus Forum 273-276:192-197. https://doi.org/10.4028/www.scientific.net/ ddf.273-276.192

Sandhyarani N (2019) Surface modification methods for electrochemical biosensors. Electrochem Biosens. https://doi.org/10.1016/ b978-0-12-816491-4.00003-6

Savi BM, Rodrigues L, Bernardin AM (2018) Synthesis of ZnONPs by solgel. Process Castellón (Spain) 1(8):1-8

Saxena J, Sharma PK, Sharma MM, Singh A, Fu Y (2016) Process optimization for green synthesis of silver nanoparticles by Sclerotinia sclerotiorum MTCC 8785 and evaluation of its antibacterial properties. SpringerPlus 5(861):1-10. https://doi. org/10.1186/s40064-016-2558-X

Senol SD, Yalcin B, Ozugurlu E, Arda EL (2020) Structure, microstructure, optical and photocatalytic properties of Mn doped ZnONPs. Mater Res Express 1(1):1-18. https://doi.org/10.1088/20531591/ab5eea

Shaikh RS, Ravangave LS (2015) Effect of reaction time on some characterization of ZnONPs. Int Res J Sci Eng Spec Issue A2:187-191

Shaikh RS, Rakh RR, Ravangave LS (2016) Sol-gel precipitation synthesis of ZnONPs, their morphological changes after calcinations and antibacterial properties. Int Res J Sci Eng 4(1):31-35

Sharma SA, Kumar SK, Rajesh N (2017) A perspective on diverse adsorbent materials to recover precious palladium and the way forward. R Soc Chem Adv 7:2133-52142. https://doi. org/10.1039/C7RA10153H

Shende P, Kasture P, Gaud RS (2018) Nanoflowers: the future trend of nanotechnology for multi-applications, artificial cells. Nanomed Biotechnol 46:413-422. https://doi.org/10.1080/21691 401.2018.1428812

Sierra MJ, Herrera AP, Ojeda KA (2018) Synthesis of zinc oxide nanoparticles from mango and soursop leaf extracts. Contemp Eng Sci 11(8):395-403. https://doi.org/10.12988/ces.2018.82281

Singh RP, Hudiara IS, Rana SB (2016) Effect of calcination temperature on the structural, optical and magnetic properties of pure and Fe-doped ZnONPs. Mater Sci Pol 34(4):451-459. https:// doi.org/10.1515/msp-2016-0059

Singh J, Yadav P, Pal AK, Mishra V (2018) Water pollutants: origin and status. Sens Water Pollut Monit Role Mater. https://doi. org/10.1007/978-981-15-0671-0_2

Siswanto RNT, Akwalia PR (2017) Fabrication and characterization of zinc oxide $(\mathrm{ZnO})$ nanoparticle by sol-gel method. . IOP Conf Ser J Phys Conf Ser 853:1-5. https://doi.org/10.1088/17426596/853/1/012041
Smolkova IS, Kazantseva NE, Babayan V, Pizurova NJV, Saha P (2017) The role of diffusion-controlled growth in the formation of uniform iron oxide nanoparticles with a link to magnetic hyperthermia. Cryst Growth Des 17(5):2323-2332

Subramanian KR (2018) The crisis of consumption of natural resources. Int J Recent Innov Acad Res 2(4):8-19

Swaroop K, Somashekarappa HM (2014) Effect of pH values on surface morphology and particle size variation in $\mathrm{ZnONPs}$ synthesised by co-precipitation method. Res J Recent Sci 4:197-201

Tan ST, Umar AA, Salleh MM (2015) (001)-Faceted hexagonal ZnO nanoplate thin film synthesis and the heterogeneous catalytic reduction of 4-nitrophenol characterization. J Alloy Compd 650:299-304. https://doi.org/10.1016/j.jallcom.2015.06.280

Thanh NK, Maclean N, Mahiddine S (2014) Mechanisms of nucleation and growth of nanoparticles in solution. Chem Rev 14(15):7610-7630

Tourné-Péteilh C, Robin B, Lions M, Martinez J, Mehdi A, Subra G, Devoisselle JM (2018) Combining sol-gel and microfluidics processes for the synthesis of protein-containing hybrid microgels. Chem Commun 55:13112-13115

Tseng Y, Chuang M, Chen Y, Wu C (2012) Synthesis of 1D, 2D, and $3 \mathrm{D} \mathrm{ZnO}$ polycrystalline nanostructures using the sol-gel method. J Nanotechnol. https://doi.org/10.1155/2012/712850

Ul-Haq AN, Nadhman A, Ullah I, Mustafa G, Yasinzai M, Khan I (2017) Synthesis approaches of zinc oxide nanoparticles: the dilemma of ecotoxicity. J Nanomater 42:1-14

Umar H, Kavaz D, Rizaner N (2019) Biosynthesis of zinc oxide nanoparticles using Albizia lebbeck stem bark, and evaluation of its antimicrobial, antioxidant, and cytotoxic activities on human breast cancer cell lines. Int J Nanomed 14:87-100. https://doi. org/10.2147/IJN.S186888

UNEP-Global (2009) Marine litter: a global challenge. UNEP, Athens. ISBN 9789280730296. https://www. google.com/search?q=UNEP-Global.+ Marin e+Litte $\mathrm{r} \% 3 \mathrm{~A}+\mathrm{A}+\mathrm{Global}+\mathrm{Challenge} \% 3 \mathrm{~B}+\mathrm{UNEP} \% 3 \mathrm{~A}+\mathrm{Athen}$ $\mathrm{s} \% 2 \mathrm{C}+$ Greece $\% 2 \mathrm{C}+2009 \% 3 \mathrm{~B}+\mathrm{ISBN}+9789280730$ 296\&oq $=$ UNEP-Global. + Marine + Litter\%3A+A+Globa $1+$ Chall enge $\% 3 \mathrm{~B}+\mathrm{UNEP} \% 3 \mathrm{~A}+\mathrm{Athen} \% 2 \mathrm{C}+\mathrm{Greec}$ $\mathrm{e} \% 2 \mathrm{C}+2009 \% 3 \mathrm{~B}+\mathrm{ISBN}+9789280730296 \&$ aqs $=$ chrome..69i57 $.545 \mathrm{j} 0 \mathrm{j} 7 \&$ sourceid $=$ chrome\&ie=UTF-8. Accessed 15 April, 2020. Accessed May 2020

Verma N, Bhatia S, Bedi RK (2017) Effect of annealing temperature on ZnONPs and its applications for photocatalytic degradation of DR-31 dye. Int J Pure Appl Phys 13(1):118-122

Wang L, Zhang X (2005) Synthesis of well-aligned ZnO nanowires by simple physical vapor deposition on cc-oriented $\mathrm{ZnO}$ thin films without catalysts or additives. Appl Phys Lett 86(2):024108. https://doi.org/10.1063/1.1851607

Wang Y, Cui Z (2009) Synthesis and photoluminescence of well aligned $\mathrm{ZnO}$ nanotube arrays by a simple chemical solution method. J Phys Conf Ser 152:1-5. https://doi.org/10.1088/17426596/152/1/012021

Waqar S, Wang L, John S (2015) Piezoelectric energy harvesting from intelligent textiles. Electron Text. https://doi.org/10.1016/b9780-08-100201-8.00010-2

Westen TV, Groot RD (2018) Effect of temperature cycling on ostwald ripening. Cryst Growth Des 8(9):4952-4962. https://doi. org/10.1021/acs.cgd.8b00267

Wołowiec M, Komorowska-Kaufman M, Pruss A, Rzepa A, Bajda $\mathrm{T}$ (2019) Removal of heavy metals and metalloids from water using drinking water treatment residuals as adsorbents: a review. Minerals 9(8):1-17. https://doi.org/10.3390/min9080487

Xie J, Lin Y, Li C, Wu D, Kong H (2015) Removal and recovery of phosphate from water by activated aluminum oxide and 
lanthanum oxide. Powder Technol 269:351-357. https://doi. org/10.1016/j.powtec.2014.09.024

Yu H, Dong Y (2016) Investigation of $\mathrm{ZnO}$ nanostructures synthesized from different zinc salts. ChemXpress 9(1):091-097

Yuvaraja G, Prasad C, Vijaya Y, Subbaiah MV (2018) Application of $\mathrm{ZnO}$ nanorods as an adsorbent material for the removal of As(III) from aqueous solution: kinetics, isotherms and thermodynamic studies. Int J Ind Chem 9:17-25. https://doi.org/10.1007/s4009 0-018-0136-5

Zhang J, Huang F, Lin Z (2010) Progress of nanocrystalline growth kinetics based on oriented attachment. Nanoscale 2:18-34. https ://doi.org/10.1039/b9nr00047j.Epub2009Oct5
Zhang C, Xie B, Zou Y, Zhu D, Lei L, Zhao D, Nie H (2018) Zerodimensional, one-dimensional, two-dimensional and threedimensional biomaterials for cell fate regulation. Adv Drug Deliv Rev 132:33-56. https://doi.org/10.1016/j.addr.2018.06.020

Ziółkowska M, Milewska-Duda J, Duda JT (2016) Effect of adsorbate properties on adsorption mechanisms: computational study. Adsorption 22:589-597. https://doi.org/10.1007/s1045 0-015-9736-y

Publisher's Note Springer Nature remains neutral with regard to jurisdictional claims in published maps and institutional affiliations. 